\title{
Ground motions around a semi-circular valley partially filled with an inclined alluvial layer under SH-polarized excitation
}

\author{
Kao-Hao Chang ${ }^{1 *}$, Deng-How Tsaur $^{2}$ and Jeen-Hwa Wang ${ }^{1}$
}

\begin{abstract}
A simplified mathematical model, composed of a semi-circular valley partially filled with an inclined alluvial layer under plane $\mathrm{SH}$-wave incidence, is presented. To evaluate the site response theoretically, a rigorous series solution is derived via the region-matching technique. For angular wavefunctions constrained by an inclined free surface, the original form of Graf's addition formula is recast to arbitrarily shift the local coordinate system. The valley geometry, filling material, angle of incidence, and wave frequency are taken as significant parameters in exploring the site effect on ground motions. Also included are the frequency- and time-domain computations. Two canonical cases, the semi-circular vacant canyon and the fully filled semi-circular alluvial valley, with exact analytical solutions, and the partly horizontally filled case previously studied, are taken to be particular cases of the proposed general model. Steady-state results show that the peak amplitudes of motion may increase at low frequencies when the filling layer inclines to the illuminated region. At low-grazing incidence, the phenomenon of wave focusing becomes evident on the shadow side of the filling layer. Transient-state simulations elucidate how a sequence of surface waves travel on the topmost alluvium along opposite directions and interfere with multiple reflected waves within the filling layer.
\end{abstract}

Keywords: Ground motions; Scattering; SH waves; Partially filled valley

\section{Background}

From numerous simulations of destructive earthquakes, the seismological community has become increasingly aware of the significance of site response to seismic waves (e.g., Boore 2004). It is generally accepted that valleys (or basins) with alluvial sediments (e.g., gravel, pebbles, clays, and volcanic ashes) can amplify and prolong ground motions dramatically (e.g., Koketsu and Kikuchi 2000; Huang et al. 2005, 2007, 2009). Near-surface geological and geometrical conditions at a specific site could be partly responsible for a strong modification of ground shaking on a regional scale (e.g., Ewald et al. 2006). Unfortunately, many metropolitan (or industrial) areas are concentrated over such unfavorable sites (e.g., the Cascadia region of northwestern USA) so that they are much more prone to catastrophic seismic consequences such as

\footnotetext{
* Correspondence: khchang@earth.sinica.edu.tw

'Institute of Earth Sciences, Academia Sinica, No. 128, Sec. 2, Academia Road, Nangang, Taipei, Taiwan 11529, Republic of China

Full list of author information is available at the end of the article
}

loss of life, injury, economic damage, and environmental impact. Recent striking events are the $1999 \mathrm{M}_{\mathrm{w}}$ 7.6 Chelungpu, Taiwan earthquake (Wang 2008), the $2010 \mathrm{M}_{\mathrm{w}}$ 8.8 Maule, Chile earthquake (Boroschek et al. 2012), and the $2011 \mathrm{M}_{\mathrm{w}} 9.0$ Tohoku, Japan earthquake (Ghofrani et al. 2013). Consequently, we have learned that knowledge of valley- and basin-related site effects not only improves the prediction of ground motions but also contributes to feasible seismic hazard assessments for seismically active areas (e.g., Frischknecht et al. 2005; Wang 2006).

Since the early 1970s, a number of canonical models have been constructed to approximate the cross-sectional profiles of natural sediment-filled valleys. Among these idealized simplified models, the most popularly adopted ones are those of the fully filled type, especially those in trapezoid shapes (e.g., Bard and Bouchon 1980; Kawase and Aki 1989; Takenaka et al. 1996; Makra et al. 2005; Kham et al. 2006; Gelagoti et al. 2010). Various numerical approximation methods were devised to evaluate the 
dynamic site response (e.g., Aki and Larner 1970; Boore et al. 1971; Dravinski et al. 1991; Clements and Larsson 1994; Fu and Bouchon 2004; Dravinski 2007; Ávila-Carrera and Sánchez-Sesma 2013). Nowadays, tremendous progress in parallel processing and faster processors has boosted the growth of mesh discretization techniques. For a large-scale domain with actual subsurface velocity structures, several sophisticated numerical schemes are, no doubt, the most powerful tools to carry out the ground-motion modelling pertinent to specific earthquakes and event scenarios. Representatives of modern schemes are the finite-difference, finite-element, spectral-element, and boundary-element methods (e.g., Komatitsch and Vilotte 1998; Bielak et al. 2005; Ma et al. 2007; Moczo et al. 2007; Lee et al. 2009; Kristek et al. 2010; Pelties et al. 2010; Delépine and Semblat 2012; Virieux et al. 2012; Kham et al. 2013). Although these effective approaches are flexible, the reliability and accuracy of the numerical results from these codes have to be strictly verified via the existing benchmark solutions.

In contrast to the fully filled alluvial valleys, the partially filled valleys seem to be of little interest. However, such types of valleys are common geological/geomorphological features. Examples are the Chusal valley in the Garm region of the former USSR (see Figure five in Tucker and King 1984), the Nera River valley in the Perugia region of Italy (see Figure three in Lenti et al. 2009), and the Aterno River valley in the Abruzzo region of central Italy (see Figure nine in De Luca et al. 2005). Furthermore, the top surfaces of alluvial deposits are sometimes mildly inclined (see Figure two in Bordoni et al. 2011). These cross-sectional geometries capture the authors' attention and thereby motivate this study.

In a paper by Tsaur and Chang (2008a), the partially filled semi-circular alluvial valley served as a simplified model for the exploration of site response and wavescattering effects. Subsequently, the conceptual model was extended by Tsaur and Hsu (2013) to study alluvial valleys with semi-elliptic cross sections. Thus, this article continues along this path, looking closely at the spatial and temporal fluctuations in ground motions near a semicircular valley partially filled with an inclined alluvial layer. To the authors' knowledge, relevant topics in the literature are very rare to date, especially those approaching the subject from a theoretical perspective. On the other hand, the present model with an inclined filling layer can degenerate into the simpler model with a horizontal filling layer. However, the latter is infeasible for the former. For these reasons, the model proposed herein is important per se. Recently, Wang (2010) treated an analogous problem on the basis of Tsaur and Chang (2008a). However, Wang (2010) only dealt with the steady states limited to a fairly narrow band of low frequencies.

For the problem under consideration, the method of solution hinges on the application of the region-matching technique (RMT), which is an effective way of overcoming the intrinsic difficulty in exploiting the method of separation of variables. From a mathematical point of view, such a promising technique is beneficial in pursuing theoretical solutions to problems involving geometric cross sections incompletely coinciding with any one of the separable coordinate systems (e.g., Tsaur and Chang 2008b, 2009; Chang 2009; Tsaur et al. 2010; Tsaur 2011; Chang et al. 2013). In this study, a rigorous series solution is derived via the RMT for the plane SH-wave incidence. Suitable wavefunctions are utilized to characterize the antiplane displacements both inside and outside the valley. The enforcement of matching conditions on the soil-bedrock interface leads to the determination of unknown expansion coefficients. A parametric analysis with systematic variations in the associated parameters (angle of incidence, wave frequency, valley geometry, and filling material) is carried out to assess the influence of these parameters on the peak amplitudes of motions.

In order to shift the coordinate origins of scalar cylindrical wavefunctions, the use of Graf's addition formula (e.g., Watson 1966) is helpful to solve the multiple-scattering problems in several branches of wave physics such as elastic, electromagnetic, sound, and water waves (e.g., Varadan et al. 1978; Bostock and Kennett 1992; Martin 2006). When the angular components of the wavefunctions are not expected to meet any constraints, Graf's addition formula can be utilized straightforwardly. For full-plane problems in the context of elastodynamics, this addition formula is usually applied in a half truncated form if the expressions with sine/cosine functions are preferred over those with exponential functions (e.g., Equations 33 to 36 in Avilés and Sánchez-Sesma 1983). For half-plane cavity/inclusion problems, this formula is commonly combined with the method of images (e.g., Smerzini et al. 2009; Tsaur and Chang 2012). When the angular wavefunctions are constrained by the zerostress condition on a horizontal free surface, the original form of Graf's addition formula should be appropriately rewritten for specific arrangements of coordinate systems (e.g., Equations 15 and 16 in Tsaur and Chang 2008a). Herein, for angular wavefunctions constrained by an inclined free surface, a novel form of Graf's addition formula is derived. Such a recast version is devoted to 'arbitrary' offsets so that it is more general than those given in the literature for offsets along the vertical direction (e.g., Tsaur and Chang 2008a; Chang 2009).

The main simplifications in the adopted model lie in the two-dimensional geometric profile, excitation source, and physical properties of the media. For the valley partially filled with inclined strata, these idealizations are perhaps the most significant ones in proposing a simple model. This indeed allows theoretical manipulation to yield the displacement/stress fields throughout the entire 
domain. So far, the element-based methods have been well established and developed with plenty of in-house/ commercial codes. However, these methods cannot bypass the need for frequency-dependent discretizations. When the wavelength of the incident wave is smaller than the characteristic length scale of the region of interest, a rapidly growing number of degrees of freedom are indispensable to maintain accuracy. In standard discretized algorithms, adaptive mesh refinement and multi-grid preconditioning operations may have to be incorporated to capture the phenomena of interest while keeping the cost of a simulation tractable on the current hardware. Nevertheless, above a certain threshold frequency, the size of the discretized model may be too large (or impractical) so that the associated computational cost may become prohibitive. For the high-frequency case, the use of traditional domain/boundary discretization schemes may generate oscillatory solutions (see Engquist et al. 2009). By contrast, the semi-analytical nature of the present series solution makes the high-frequency computation very easy and efficient. With increasing frequency, only one simple manipulation is needed in the present series-based code, namely, raising the number of wavefunction expansions. The key reason for this is that by making good use of the RMT, well-defined expressions can be obtained for the wavefield components. The field solution of each individual subregion is well behaved because the governing equation and all the boundary conditions (except for those at the soil-bedrock interface and circular-arc free surface) are fulfilled innately.

The RMT proposed herein can be conveniently applied to deal with more $\mathrm{SH}$-wave problems involving other types of partially filled models consisting purely of circular-arc lines or those made up of both curves and straight lines. As to P- and SV-wave incidence, the RMT may be applicable if the explicit expressions of wavefunctions in specific coordinate systems are available. However, such wavefunctions in the open region have to inherently satisfy the zero-stress condition on the horizontal ground surface, while those in the enclosed region have to intrinsically fulfill the traction-free condition at the surface of the alluvium. This is a fundamental requirement for extension of the applicability of the RMT to in-plane wave propagation.

The model profile assumed in this paper might be the most obvious one in a first investigation for an inclined alluvial layer partially filling the valley. Because our interest focuses on the site-amplification effect, the potential applications of the current model may cover a wide range of geophysical, environmental, and engineering disciplines. It is known that during strong ground motions, site amplification is one of the root causes responsible for the instability of steep rocky slopes, the loss of cohesion, the imbalance of stress-strength state, the reduction of frictional resistance of the substrate, and the mobilization of superficial loose materials (e.g., Keefer et al. 2006; Chigira et al. 2010; Hovius and Meunier 2012). Thus, the current analysis lays a solid foundation for related studies. Typical examples are those concerning the earthquake-induced slope failures, landslides, and debris flows. However, their dynamic processes involve a succession of granular materials, ranging in size from silts and clays to gravel, pebbles, and even boulders. Opportunities for these situations may be provided by using the individual-based approaches such as the offlattice method, the discrete (or distinct) element method, the material point method, and the particle method (see Jing and Stephansson 2007; Andersen and Andersen 2010; Marketos and O'Sullivan 2013; Takekawa et al. 2013).

\section{Methods}

\section{Theoretical formulations}

Consider a semi-infinite medium bounded by the horizontal ground surface, inlaid with an infinitely long, semi-circular valley (of radius $a$ ) partially filled with an inclined alluvial layer (see Figure 1). An infinite train of plane $\mathrm{SH}$ waves (with an angular frequency $\omega$ ) is incident upon this valley at an angle $\alpha$ to the $y_{1}$-axis. The origins of global coordinate systems $\left(x_{1}, y_{1}\right)$ and $\left(r_{1}, \theta_{1}\right)$ are set at the center of the valley, while those of local coordinate systems $\left(x_{2}, y_{2}\right)$ and $\left(r_{2}, \theta_{2}\right)$ are set at the center of the alluvium surface. Relative positions between the global and local coordinate systems are expressed as $\left(r_{e}, \theta_{e}\right)$. The angular positions of the soil-bedrock interface range from $\beta_{1}$ to $\beta_{2}$. All the media involved are assumed to be isotropic, homogeneous, and linearly elastic. The shear modulus, mass density, and shearwave velocity are given by $\mu_{j}, \rho_{j}$, and $c_{j}=\sqrt{\mu_{j} / \rho_{j}}$, respectively, where the subscripts, $j=1$ and 2 , stand for those in the half plane and alluvium, respectively. The contact interface between the two materials is supposed to be perfectly bonded. Note that for the clarity of each

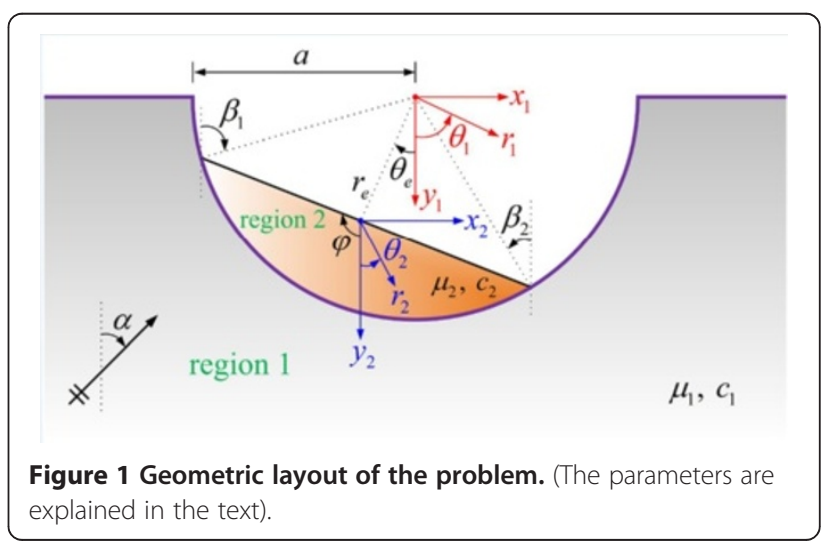


symbol shown in Figure 1, the inclination of the filling layer is somewhat exaggerated.

\section{Derivation for the general case}

As seen in Figure 1, the half plane is divided into two regions, an open region 1 and an enclosed region 2 . In these two regions, the steady-state out-of-plane motions are required to satisfy the governing Helmholtz equations, namely,

$$
\nabla^{2} u_{j}+k_{j}^{2} u_{j}=0, \quad j=1,2,
$$

where $\nabla^{2}$ is the 2-D Laplacian and $k_{j}=\omega / c_{j}$ is the shear wavenumber. Throughout this work, the time-harmonic factor $\exp (i \omega t)$ is assumed and suppressed.

The zero-stress boundary conditions on the horizontal ground surface, the curved surface of the valley, and the surface of the alluvium are as follows:

$$
\begin{aligned}
\tau_{\theta_{1} z}^{(1)} & =\frac{\mu_{1}}{r_{1}} \frac{\partial u_{1}\left(r_{1}, \theta_{1}\right)}{\partial \theta_{1}}=0, \quad \theta_{1}= \pm \frac{\pi}{2}, \quad r_{1}>a, \\
\tau_{r_{1} z}^{(1)} & =\mu_{1} \frac{\partial u_{1}\left(r_{1}, \theta_{1}\right)}{\partial r_{1}} \\
& =0, \quad-\frac{\pi}{2} \leq \theta_{1} \leq \beta_{1}, \quad \beta_{2} \leq \theta_{1} \leq \frac{\pi}{2}, \quad r_{1}=a, \\
\tau_{\theta_{2} z}^{(2)} & =\frac{\mu_{2}}{r_{2}} \frac{\partial u_{2}\left(r_{2}, \theta_{2}\right)}{\partial \theta_{2}}=0, \theta_{2}=-\varphi, \pi-\varphi .
\end{aligned}
$$

For the half-plane medium without any surface/subsurface anomalies, the free-field displacement $u^{\mathrm{F}}$ can be expressed as a sum of the incident waves and their reflected waves from the horizontal ground surface, that is,

$$
u^{\mathrm{F}}\left(r_{1}, \theta_{1}\right)=\exp \left[i k_{1} r_{1} \cos \left(\theta_{1}+\alpha\right)\right]+\exp \left[-i k_{1} r_{1} \cos \left(\theta_{1}-\alpha\right)\right] .
$$

Employing the Jacobi-Anger expansion (Abramowitz and Stegun 1972), Equation 5 can be rewritten as

$$
\begin{aligned}
u^{\mathrm{F}}\left(r_{1}, \theta_{1}\right) & =2 \sum_{n=0}^{\infty} \varepsilon_{n}(-1)^{n} J_{2 n}\left(k_{1} r_{1}\right) \cos (2 n \alpha) \cos \left(2 n \theta_{1}\right) \\
& -4 i \sum_{n=0}^{\infty}(-1)^{n} J_{2 n+1}\left(k_{1} r_{1}\right) \sin [(2 n+1) \alpha] \sin \left[(2 n+1) \theta_{1}\right],
\end{aligned}
$$

where $\varepsilon_{n}$ is the Neumann factor (equal to 1 if $n=0$ and 2 if $n \geq 1)$ and $J_{n}(\cdot)$ denotes the $n$th order Bessel function of the first kind. Note that Equation 6 inherently satisfies the traction-free condition on the horizontal ground surface (Equation 2).

The total scattered field $u^{\mathrm{S}}$ in the open region 1 may be separated into two parts, $u^{\mathrm{S} 0}$ and $u^{\mathrm{S} 2}$. Thus,

$$
u^{\mathrm{S}}\left(r_{1}, \theta_{1}\right)=u^{\mathrm{S} 0}\left(r_{1}, \theta_{1}\right)+u^{\mathrm{S} 2}\left(r_{1}, \theta_{1}\right) .
$$

The first component $u^{\mathrm{S} 0}$ represents the scattered fields excluding the effect of region 2. It corresponds to the scattered fields regarding the case of completely empty semi-circular canyons, that is,

$$
\begin{aligned}
u^{S 0}\left(r_{1}, \theta_{1}\right) & =\sum_{n=0}^{\infty} \tilde{A}_{n} H_{2 n}^{(2)}\left(k_{1} r_{1}\right) \cos \left(2 n \theta_{1}\right) \\
& +\sum_{n=0}^{\infty} \tilde{B}_{n} H_{2 n+1}^{(2)}\left(k_{1} r_{1}\right) \sin \left[(2 n+1) \theta_{1}\right],
\end{aligned}
$$

where $H_{n}^{(2)}(\cdot)$ is the $n$th order Hankel function of the second kind, and the exact analytical expressions for scattered coefficients $\tilde{A}_{n}$ and $\tilde{B}_{n}$ have been derived by Trifunac (1973) as

$$
\begin{aligned}
& \tilde{A}_{n}=-2 \varepsilon_{n}(-1)^{n} \frac{J_{2 n}^{\prime}\left(k_{1} a\right)}{H_{2 n}^{(2)^{\prime}}\left(k_{1} a\right)} \cos (2 n \alpha), \\
& \tilde{B}_{n}=4 i(-1)^{n} \frac{J_{2 n+1}^{\prime}\left(k_{1} a\right)}{H_{2 n+1}^{(2)^{\prime}}\left(k_{1} a\right)} \sin [(2 n+1) \alpha],
\end{aligned}
$$

in which the primes stand for differentiation with respect to the arguments of the corresponding functions.

The second component $u^{\mathrm{S} 2}$ means the scattered fields induced by the existence of region 2 , and its proper wavefunction can be written as

$$
\begin{aligned}
u^{\mathrm{S} 2}\left(r_{1}, \theta_{1}\right) & =\sum_{n=0}^{\infty} A_{n} H_{2 n}^{(2)}\left(k_{1} r_{1}\right) \cos \left(2 n \theta_{1}\right) \\
& +\sum_{n=0}^{\infty} B_{n} H_{2 n+1}^{(2)}\left(k_{1} r_{1}\right) \sin \left[(2 n+1) \theta_{1}\right],
\end{aligned}
$$

in which the complex expansion coefficients $A_{n}$ and $B_{n}$ are unknown.

In region 1, the displacement of the resultant wavefield $u_{1}$, which is the conjunction of the free wavefield and the total scattered wavefield, can be expressed as

$$
u_{1}\left(r_{1}, \theta_{1}\right)=u^{\mathrm{F}}\left(r_{1}, \theta_{1}\right)+u^{\mathrm{S}}\left(r_{1}, \theta_{1}\right) .
$$

In region 2 , the displacement of wavefield $u_{2}$, which satisfies the Helmholtz equation (Equation 1) and the stress-free boundary conditions (Equation 4) on the upper face of the filling layer, is given by

$$
u_{2}\left(r_{2}, \theta_{2}\right)=\sum_{n=0}^{\infty} C_{n} J_{n}\left(k_{2} r_{2}\right) \cos \left[n\left(\theta_{2}+\varphi\right)\right]
$$

where the complex expansion coefficients $C_{n}$ will be determined. 
In order to rewrite Equation 13 in terms of $\left(r_{1}, \theta_{1}\right)$, the necessary coordinate transformation from $\left(r_{2}, \theta_{2}\right)$ to $\left(r_{1}, \theta_{1}\right)$ is accomplished via Graf's addition formula for Bessel functions (section 11.3, p 360, Equation 2 in Watson 1966), which is recast in an appropriate form as follows:

$$
\begin{aligned}
& J_{n}\left(k_{2} r_{2}\right) \cos \left[n\left(\theta_{2}+\varphi\right)\right] \\
& \quad=\sum_{m=0}^{\infty} J_{m}\left(k_{2} r_{1}\right)\left[F_{m, n}^{C} \cos \left(m \theta_{1}\right)+F_{m, n}^{S} \sin \left(m \theta_{1}\right)\right],
\end{aligned}
$$

where the functions $F_{m, n}^{C}$ and $F_{m, n}^{S}$ are given in Appendix 1 (see Equations 39 and 40). Note that Equation 15 in Tsaur and Chang (2008a) is just the special case of Equation 14. Because the coordinate-transformation formula adopted herein is more compact than that in Wang (2010), the following solution enables a more effective computational performance, notably for high frequencies.

Considering the stress continuity condition on the soil-bedrock interface, we have

$$
\tau_{r_{1} z}^{(1)}\left(r_{1}, \theta_{1}\right)=\tau_{r_{1} z}^{(2)}\left(r_{1}, \theta_{1}\right), \quad \beta_{1} \leq \theta_{1} \leq \beta_{2}, \quad r_{1}=a .
$$

Applying the zero-stress conditions on the two circular-arc free surfaces of the valley (Equation 3) to the left-hand side of Equation 15, multiplying a sequence of weight functions and integrating over the corresponding bounds lead to

$$
\begin{array}{r}
\int_{-\pi / 2}^{\pi / 2} \tau_{r_{1} z}^{(1)}\left(a, \theta_{1}\right) \cos \left(2 q \theta_{1}\right) d \theta_{1}=\int_{\beta_{1}}^{\beta_{2}} \tau_{r_{1} z}^{(2)}\left(a, \theta_{1}\right) \cos \left(2 q \theta_{1}\right) d \theta_{1}, \\
q=0,1, \ldots, \\
(16) \\
\int_{-\pi / 2}^{\pi / 2} \tau_{r_{12} z}^{(1)}\left(a, \theta_{1}\right) \sin \left[(2 q+1) \theta_{1}\right] d \theta_{1}=\int_{\beta_{1}}^{\beta_{2}} \tau_{r_{12} z}^{(2)}\left(a, \theta_{1}\right) \sin \left[(2 q+1) \theta_{1}\right] d \theta_{1}, \\
q=0,1, \ldots .
\end{array}
$$

Employing the orthogonal property of sine/cosine functions and performing some algebraic manipulations yield the following relations between the unknown expansion coefficients:

$$
\begin{aligned}
& A_{n}=\frac{\varepsilon_{n} \mu_{2}}{\pi H_{2 n}^{(2)^{\prime}}\left(k_{1} a\right) \mu_{1}} \sum_{p=0}^{\infty} C_{p} \tilde{G}_{p, 2 n}^{C}, \\
& B_{n}=\frac{2 \mu_{2}}{\pi H_{2 n+1}^{(2)^{\prime}}\left(k_{1} a\right) \mu_{1}} \sum_{p=0}^{\infty} C_{p} \tilde{G}_{p, 2 n+1}^{S},
\end{aligned}
$$

in which

$$
\begin{aligned}
& \tilde{G}_{p, n}^{C}=\sum_{m=0}^{\infty}\left(F_{m, p}^{C} I_{m, n}^{C}+F_{m, p}^{S} I_{m, n}^{S C}\right) J_{m}^{\prime}\left(k_{2} a\right), \\
& \tilde{G}_{p, n}^{S}=\sum_{m=0}^{\infty}\left(F_{m, p}^{C} I_{n, m}^{S C}+F_{m, p}^{S} I_{m, n}^{S}\right) J_{m}^{\prime}\left(k_{2} a\right),
\end{aligned}
$$

and detailed expressions are given in Appendix 1 (see Equations 39 to 43 ).

Similarly, the enforcement of displacement continuity across the soil-bedrock interface is required, that is,

$$
u_{1}\left(r_{1}, \theta_{1}\right)=u_{2}\left(r_{1}, \theta_{1}\right), \quad \beta_{1} \leq \theta_{1} \leq \beta_{2}, \quad r_{1}=a .
$$

In light of this, utilizing a succession of sine/cosine functions and integrating over the range $\left[\beta_{1}, \beta_{2}\right]$ give

$$
\begin{array}{r}
\int_{\beta_{1}}^{\beta_{2}} u_{1}\left(a, \theta_{1}\right) \cos \left(2 q \theta_{1}\right) d \theta_{1}=\int_{\beta_{1}}^{\beta_{2}} u_{2}\left(a, \theta_{1}\right) \cos \left(2 q \theta_{1}\right) d \theta_{1}, \\
q=0,1, \ldots, \\
(23) \\
\int_{\beta_{1}}^{\beta_{2}} u_{1}\left(a, \theta_{1}\right) \sin \left[(2 q+1) \theta_{1}\right] d \theta_{1}=\int_{\beta_{1}}^{\beta_{2}} u_{2}\left(a, \theta_{1}\right) \sin \left[(2 q+1) \theta_{1}\right] d \theta_{1}, \\
q=0,1, \ldots .
\end{array}
$$

Applying Equations 18 and 19 to eliminate the scattering coefficients $\left(A_{n}\right.$ and $\left.B_{n}\right)$, using the Wronskian relations for Bessel and Hankel functions (e.g., p 113, Equation 5.9.3 in Lebedev 1965), and rearranging the results in two coupled sets of infinite, linear, and algebraic equations with unknown coefficients $C_{n}$ yield

$$
\begin{aligned}
& \sum_{n=0}^{\infty} C_{n} R_{q, n}^{C}=L_{q}^{C}, \quad q=0,1, \ldots, \\
& \sum_{n=0}^{\infty} C_{n} R_{q, n}^{S}=L_{q}^{S}, \quad q=0,1, \ldots,
\end{aligned}
$$

where the pertinent functions used are shown in Appendix 2 for conciseness (see Equations 44 to 47).

After truncating the infinite series in Equations 25 and 26 properly, the expansion coefficients $C_{n}$ can be evaluated by standard matrix techniques. For numerical computations, it is necessary to truncate the infinite summation to a finite number of terms. Summation indices $n$ and weighting indices $q$ in Equations 25 and 26 are truncated after $2 N-1$ and $N-1$ terms, respectively. Therefore, Equations 25 and 26 constitute a system of 2 $N$ equations with $2 N$ unknowns. Once the coefficients $C_{n}$ are found, the expansion coefficients $A_{n}$ and $B_{n}$ can be evaluated straightforwardly via Equations 18 and 19 .

For the specific location, the displacement amplitude | $u \mid$ is evaluated from the expressions of corresponding wavefields (see Equations 12 and 13), that is, 


$$
|u|=\left\{\begin{array}{ll}
\left|u_{1}\right|=\sqrt{\left[\operatorname{Re}\left(u_{1}\right)\right]^{2}+\left[\operatorname{Im}\left(u_{1}\right)\right]^{2}}, & \text { for region 1 } \\
\left|u_{2}\right|=\sqrt{\left[\operatorname{Re}\left(u_{2}\right)\right]^{2}+\left[\operatorname{Im}\left(u_{2}\right)\right]^{2}}, & \text { for region 2 }
\end{array},\right.
$$

where $\operatorname{Re}(\cdot)$ and $\operatorname{Im}(\cdot)$ denote the real and imaginary parts of complex expressions, respectively. Note that for the computed results given below, the free wavefield $u^{\mathrm{F}}$ is directly evaluated from Equation 5 .

\section{Degeneration for limiting cases \\ Vacant canyon}

When the filling layer in the valley is absent (i.e., $\beta_{1}=\beta_{2}=0$ ), the model is merely the semi-circular vacant canyon. Hence, the expansion coefficients are $A_{n}=0, B_{n}=0$, and $C_{n}=0$. This gives $u^{\mathrm{S} 2}=0$, and only $u^{\mathrm{S} 0}$ exists. Thus, the series solution derived for such a limiting case is the exact analytical solution derived by Trifunac (1973).

\section{Fully filled alluvial valley}

When the valley is entirely filled with alluvial soils (i.e., $\left.\varphi=-\beta_{1}=\beta_{2}=\pi / 2\right)$, the displacement field shown in Equation 13 for region 2 can be rewritten as

$$
\begin{aligned}
u_{2}\left(r_{1}, \theta_{1}\right) & =\sum_{n=0}^{\infty}(-1)^{n} C_{2 n} J_{2 n}\left(k_{2} r_{1}\right) \cos \left(2 n \theta_{1}\right) \\
& -\sum_{n=0}^{\infty}(-1)^{n} C_{2 n+1} J_{2 n+1}\left(k_{2} r_{1}\right) \sin \left[(2 n+1) \theta_{1}\right]
\end{aligned}
$$

Replacing the symbols of the unknowns in Equation 28 via

$$
\begin{aligned}
& \hat{C}_{n}=(-1)^{n} C_{2 n}, \\
& \hat{D}_{n}=-(-1)^{n} C_{2 n+1},
\end{aligned}
$$

and simplifying Equations 25 and 26, the expansion coefficients for region 2 are

$$
\hat{C}_{n}=-\frac{4 i \varepsilon_{n}(-1)^{n} \cos (2 n \alpha)}{\pi a\left[\mu_{1} J_{2 n}\left(k_{2} a\right) H_{2 n}^{(2)^{\prime}}\left(k_{1} a\right)-\mu_{2} J_{2 n}^{\prime}\left(k_{2} a\right) H_{2 n}^{(2)}\left(k_{1} a\right)\right]},
$$

$$
\hat{D}_{n}=-\frac{8(-1)^{n} \sin [(2 n+1) \alpha]}{\pi a\left[\mu_{1} J_{2 n+1}\left(k_{2} a\right) H_{2 n+1}^{(2)^{\prime}}\left(k_{1} a\right)-\mu_{2} J_{2 n+1}^{\prime}\left(k_{2} a\right) H_{2 n+1}^{(2)}\left(k_{1} a\right)\right]} .
$$

Based on Equations 18, 19, 31, and 32, Equation 7 gives

$$
\begin{aligned}
\hat{A}_{n} & =\tilde{A}_{n}+A_{n} \\
& =-\frac{2 \varepsilon_{n}(-1)^{n} \cos (2 n \alpha) W_{2 n}}{\mu_{1} J_{2 n}\left(k_{2} a\right) H_{2 n}^{(2)^{\prime}}\left(k_{1} a\right)-\mu_{2} J_{2 n}^{\prime}\left(k_{2} a\right) H_{2 n}^{(2)}\left(k_{1} a\right)},
\end{aligned}
$$

$$
\begin{aligned}
\hat{B}_{n} & =\tilde{B}_{n}+B_{n} \\
& =\frac{4 i(-1)^{n} \sin [(2 n+1) \alpha] W_{2 n+1}}{\mu_{1} J_{2 n+1}\left(k_{2} a\right) H_{2 n+1}^{(2)^{\prime}}\left(k_{1} a\right)-\mu_{2} J_{2 n+1}^{\prime}\left(k_{2} a\right) H_{2 n+1}^{(2)}\left(k_{1} a\right)},
\end{aligned}
$$

in which

$$
W_{n}=\mu_{1} J_{n}\left(k_{2} a\right) J_{n}^{\prime}\left(k_{1} a\right)-\mu_{2} J_{n}^{\prime}\left(k_{2} a\right) J_{n}\left(k_{1} a\right) .
$$

Equations 31 to 34 are the solutions of simultaneous equations derived by Trifunac (1971) for the fully filled semi-circular alluvial valleys.

\section{Horizontal free surface}

When the filling materials in regions 1 and 2 have the same mechanical properties (i.e., $\rho_{1}=\rho_{2}$ and $c_{1}=c_{2}$, and thus $\mu_{1}=\mu_{2}$ and $k_{1}=k_{2}$ ), a fully filled alluvial valley becomes a horizontal free surface without any surficial discontinuities. Clearly, in such a condition, $\hat{A}_{n}$ and $\hat{B}_{n}$ in Equations 33 and 34 are zero because $W_{n}$ in Equation 35 becomes zero. This signifies that all the scattered waves vanish in the absence of alluvium. By applying the Wronskian relation (Lebedev 1965) to simplify the denominators of Equations 31 and 32, and then utilizing Equations 28 to 30, the wavefields in region 2 recover the free wavefields shown in Equation 6.

\section{Results and discussion}

In this section, the dimensionless frequency $\eta$ is defined as the ratio of the maximum width of the valley to the incident wavelength $\lambda_{1}$, that is,

$$
\eta=\frac{k_{1} a}{\pi}=\frac{2 a}{\lambda_{1}} .
$$

The displacement amplitude of the incident waves is taken to be one unit. All the following simulations are done using a desktop computer with a $3.40 \mathrm{GHz}$ Intel $^{\circ}$ Core $^{\text {ma }}$ i7-3770 CPU (Intel, Santa Clara, CA, USA) and 8.00 GB RAM under Windows 7 64-bit OS and MATHEMATICA programming environment (Wolfram, Champaign, IL, USA).

\section{Convergence test}

At the initial stage of calculations, a number of convergence tests are performed. The inner series with indices $m$ (see Equations 48 and 49 in Appendix 2) are truncated and bounded from 0 to $M-1$ terms. These internal sums should be accurately calculated via numerical testing for their convergence, thereby leaving only one parameter 
(i.e., the summation index $n$ ) to remove the problem of relative convergence.

Take the moderately filled case $\left(\beta_{1}=-40^{\circ}\right.$ and $\beta_{2}=$ $\left.55^{\circ}\right)$ with $\rho_{2} / \rho_{1}=0.82$ and $c_{2} / c_{1}=0.4$ as an example. At first, the value of the outer truncation index $N$ is fixed, then the displacement amplitudes along the horizontal, curved, and inclined traction-free surfaces are evaluated with respect to increasing inner truncation index $M$. During the convergence test, only the horizontally incident cases are checked because they take more truncation terms than others to reach convergence. The relative error is defined to be

$$
E_{r}=\frac{\left|V_{p}-V_{f}\right|}{V_{f}} \times 100 \%
$$

in which $V_{p}$ and $V_{f}$ denote the two adjacent computed values of displacement amplitudes. Successive computations are performed until the target relative error is met. Table 1 displays the values of displacement amplitudes for $\alpha=90^{\circ}$ at five specific positions, where $P_{1}$ to $P_{5}$ are located at $x_{1} / a=-1.5,-0.95,0.1,0.95$, and 1.5 , respectively, that is, $P_{1}$ and $P_{5}$ are placed outside the valley and $P_{2}$ to $P_{4}$ inside. The outer truncation index is chosen at $N=18$ for the low-frequency case $(\eta=1)$ and $N=82$ for the high-frequency one $(\eta=10)$. The errors listed in Table 1 mean that the maximum values of relative errors are calculated for the displacement amplitudes at 800 equally spaced locations, ranging between $x_{1} / a=-4$ and 4. As seen in Table 1, numerical results converge to at least 12 significant digits at $M=30$ for $\eta=1$ and at $M=$ 135 for $\eta=10$. When the number of inner truncation terms is sufficient, the coordinate-transformation process is carried out accurately. Based on further numerical tests for other filling levels, $M=200$ is adequate to produce reliable results at higher frequencies $(14 \leq \eta \leq 16)$.

The outer truncation index $N$ dominates the fulfillment of continuity conditions (across the soil-bedrock interface) and zero-stress conditions (across the circulararc surface of the valley). Table 2 shows the variations in maximum relative errors and computational costs when $N$ increases. In Table 2, the maximum relative error is smaller than $0.1 \%$ after $N=16$ at $\eta=0.5$ and after $N=$ 138 at $\eta=12$. Overall, the computation time and memory gradually increase with $N$. Considering a reasonable balance between computational efficiency and accuracy, the convergence criterion for $N$ is that the maximum relative error falls below the threshold value of $0.1 \%$, which is acceptable for engineering purposes.

\section{Validation for the completely empty case}

When the upper surface of the alluvial layer approaches the bottom of the valley, the computed results for the extremely lowly filled valley can be exploited to approximate
Table 1 Values of pertinent parameters for different inner truncation indices

\begin{tabular}{|c|c|c|c|}
\hline \multirow[t]{2}{*}{$M$} & \multicolumn{3}{|c|}{ Low-frequency case $(\eta=1)$} \\
\hline & $P_{1}$ & $P_{2}$ & $P_{3}$ \\
\hline 22 & 1.190294289687 & 3.494137369096 & 3.951746767643 \\
\hline 24 & 1.190267947613 & 3.494149108380 & 3.951352255433 \\
\hline 26 & 1.190267465292 & 3.494149365072 & 3.951351221806 \\
\hline 28 & 1.190267458947 & 3.494149368736 & 3.951351210176 \\
\hline 30 & 1.190267458962 & 3.494149368728 & 3.951351210224 \\
\hline 32 & 1.190267458962 & 3.494149368728 & 3.951351210224 \\
\hline \multirow[t]{2}{*}{34} & 1.190267458962 & 3.494149368728 & 3.951351210224 \\
\hline & \multicolumn{3}{|c|}{ High-frequency case $(\eta=10)$} \\
\hline 105 & 3.852549926081 & 3.798895709292 & 1.426239484464 \\
\hline 110 & 3.852670425350 & 3.798897978157 & 1.425983729509 \\
\hline 115 & 3.852672532000 & 3.798897841089 & 1.425996636539 \\
\hline 120 & 3.852672269462 & 3.798898139431 & 1.425999548587 \\
\hline 125 & 3.852672241997 & 3.798898064628 & 1.425997735750 \\
\hline 130 & 3.852672217055 & 3.798898082794 & 1.425997818638 \\
\hline 135 & 3.852672217334 & 3.798898082637 & 1.425997818635 \\
\hline \multirow[t]{3}{*}{140} & 3.852672217334 & 3.798898082637 & 1.425997818635 \\
\hline & \multicolumn{3}{|c|}{ Low-frequency case $(\eta=1)$} \\
\hline & $P_{4}$ & $P_{5}$ & Error \\
\hline 22 & 0.500030672653 & 0.891741857615 & 75.0368864083 \\
\hline 24 & 0.499811004983 & 0.891382133938 & 0.187004610300 \\
\hline 26 & 0.499810783582 & 0.891381807308 & $4.47556145287 \times 10^{-4}$ \\
\hline 28 & 0.499810781914 & 0.891381803982 & $3.63315136472 \times 10^{-6}$ \\
\hline 30 & 0.499810781927 & 0.891381804004 & $1.61204492590 \times 10^{-8}$ \\
\hline 32 & 0.499810781927 & 0.891381804004 & $3.13190321119 \times 10^{-9}$ \\
\hline \multirow[t]{2}{*}{34} & 0.499810781927 & 0.891381804004 & $<10^{-10}$ \\
\hline & \multicolumn{3}{|c|}{ High-frequency case $(\eta=10)$} \\
\hline 105 & 0.293334113173 & 0.421453729093 & 3.09171329268 \\
\hline 110 & 0.293284625937 & 0.421398985186 & $1.79321185135 \times 10^{-2}$ \\
\hline 115 & 0.293286828405 & 0.421402108231 & $9.05131671893 \times 10^{-4}$ \\
\hline 120 & 0.293286952154 & 0.421402250130 & $2.04211367705 \times 10^{-4}$ \\
\hline 125 & 0.293286901718 & 0.421402154841 & $1.27127443954 \times 10^{-4}$ \\
\hline 130 & 0.293286913103 & 0.421402167992 & $5.81262142562 \times 10^{-6}$ \\
\hline 135 & 0.293286912958 & 0.421402167820 & $4.96550950368 \times 10^{-8}$ \\
\hline 140 & 0.293286912958 & 0.421402167820 & $<10^{-10}$ \\
\hline
\end{tabular}

$M$, inner truncation index; $P_{1}$ to $P_{5}$, displacement amplitudes at five specific positions; Error, maximum relative error (in percent) for 800 equally spaced locations.

those for the completely empty canyon. Several cases shown in Trifunac (1973), with an exact analytical solution to antiplane scattering induced by a semi-circular canyon, are taken as validation examples. Computed results pertinent to the case of $\eta=0.75$ at $\alpha=30^{\circ}$ are given in Figure 2a. The angular position $\beta_{1}$ of the inclined layer is $-20^{\circ},-15^{\circ}$, and $-5^{\circ}$ while $\beta_{2}$ is $25^{\circ}, 20^{\circ}$, and $10^{\circ}$, 
Table 2 Values of pertinent parameters for different outer truncation indices

\begin{tabular}{lccc}
\hline $\boldsymbol{N}$ & \multicolumn{3}{c}{ Low-frequency case $(\boldsymbol{\eta}=\mathbf{0 . 5})$} \\
\cline { 2 - 4 } & Error & Elapsed time & Memory \\
\hline 6 & 2.27 & 0.85 & 11.11 \\
8 & 0.63 & 1.20 & 12.19 \\
12 & 0.29 & 1.32 & 14.06 \\
16 & 0.017 & 1.63 & 15.62 \\
28 & 0.0026 & 3.23 & 20.70 \\
\hline & & High-frequency case $(\boldsymbol{\eta}=\mathbf{1 2})$ & \\
\hline 70 & 26.64 & 23.89 & 44.46 \\
78 & 13.95 & 25.49 & 46.61 \\
88 & 2.93 & 29.87 & 52.79 \\
100 & 1.41 & 36.04 & 59.74 \\
120 & 0.51 & 46.46 & 72.13 \\
126 & 0.12 & 49.89 & 78.04 \\
138 & 0.07 & 57.51 & 86.07 \\
148 & 0.0086 & 64.44 & 93.09 \\
\hline
\end{tabular}

$\mathrm{N}$, outer truncation index; Error, maximum relative error in percent; Elapsed time, computation time in seconds; Memory, memory in megabytes.

respectively. The values of $\rho_{2} / \rho_{1}$ and $c_{2} / c_{1}$ are 0.82 and 0.4 , respectively. The specific locations on the valley surface ranging between $x_{1} / a=-1$ and 1 are displayed by a bold black line. As seen in Figure 2a, the present results tend to coincide with those of Trifunac (1973) when the filling level of alluvial layer falls gradually towards the valley bottom. Obviously, these results confirm the present formulism.

\section{Validation for the fully filled case}

In contrast, when the upper surface of the alluvial layer approaches the ground level, the computed results can approximate those for the fully filled valley. The exact analytical solution to $\mathrm{SH}$-wave scattering induced by a semi-circular alluvial valley obtained by Trifunac (1971) serves as the benchmark. The analytical solutions are displayed by open circles in Figure 2b. Results for $\eta=0.5$ at $\alpha=30^{\circ}$ when $\beta_{1}=-87^{\circ},-89^{\circ}$, and $-89.999^{\circ}$ with $\beta_{2}=$ $80^{\circ}, 86^{\circ}$, and $89^{\circ}$, respectively, are shown in Figure $2 \mathrm{~b}$. The values of $\rho_{2} / \rho_{1}$ and $c_{2} / c_{1}$ are 0.6667 and 0.5 , respectively. Figure $2 \mathrm{~b}$ exhibits good consistency between the present results and those of Trifunac (1971) when the filling level of alluvial layer rises gradually towards the top of the valley. Figure $2 \mathrm{~b}$ thus suggests that the present model is valid.

\section{Surface motions in the frequency domain}

The Seattle basin in northwestern USA (e.g., Pratt et al. 2003) is a good example for numerical simulations. Three types of materials are chosen, and the mechanical properties such as $\rho_{2} / \rho_{1}, c_{2} / c_{1}$, and $\mu_{2} / \mu_{1}$ are listed in

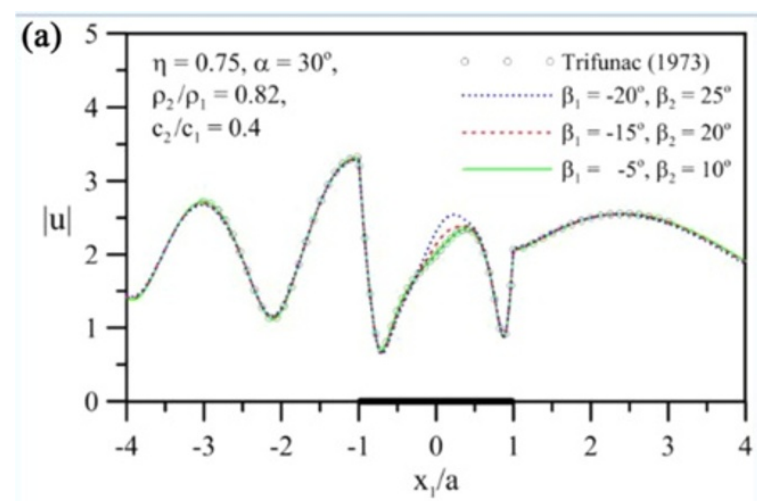

(b)

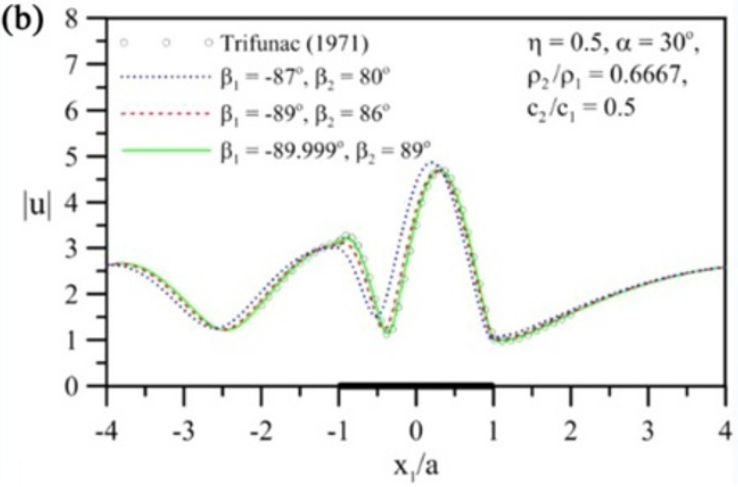

Figure 2 Surface motions versus $x_{1} / a$ at $a=30^{\circ}$. (a) The completely empty case. (b) The fully filled case. The solid, dashed, and dotted lines display the results of this study and the open circles show those obtained by Trifunac $(1971,1973)$.

Table 3. The alluvial stratum becomes softer from materials 1 to 3 . Three models, models 1 to 3 , are illustrated in Figure 3a. Model 1 is a lowly filled case with $\beta_{1}=-$ $25^{\circ}$ and $\beta_{2}=40^{\circ}$, model 2 an intermediately filled case with $\beta_{1}=-45^{\circ}$ and $\beta_{2}=60^{\circ}$, and model 3 , a highly filled case with $\beta_{1}=-60^{\circ}$ and $\beta_{2}=75^{\circ}$.

The computed results revealing the effect of the filling level of soft alluvial layer (i.e., material 3) on the displacement amplitudes are shown in Figure $3 \mathrm{~b}, \mathrm{c}, \mathrm{d}, \mathrm{e}, \mathrm{f}$ for $\alpha=0^{\circ}, 45^{\circ}, 90^{\circ},-45^{\circ}$, and $-90^{\circ}$, respectively, and when $\eta=1$. Owing to the valley asymmetry, asymmetric motions under symmetric excitation can be found in Figure 3b. For obliquely incident cases in Figure 3c,e, the peak amplitudes of motions increase with the filling level. In Figure 3b,c,d,e,f, the number of local maximum

Table 3 Mechanical properties for the three materials adopted

\begin{tabular}{lccc}
\hline & $\boldsymbol{\rho}_{\mathbf{2}} / \boldsymbol{\rho}_{\mathbf{1}}$ & $\boldsymbol{c}_{\mathbf{2}} / \boldsymbol{c}_{\mathbf{1}}$ & $\boldsymbol{\mu}_{\mathbf{2}} / \boldsymbol{\mu}_{\mathbf{1}}$ \\
\hline Material 1 & 0.88 & 0.8 & 0.5632 \\
Material 2 & 0.85 & 0.6 & 0.3060 \\
Material 3 & 0.82 & 0.4 & 0.1312 \\
\hline
\end{tabular}



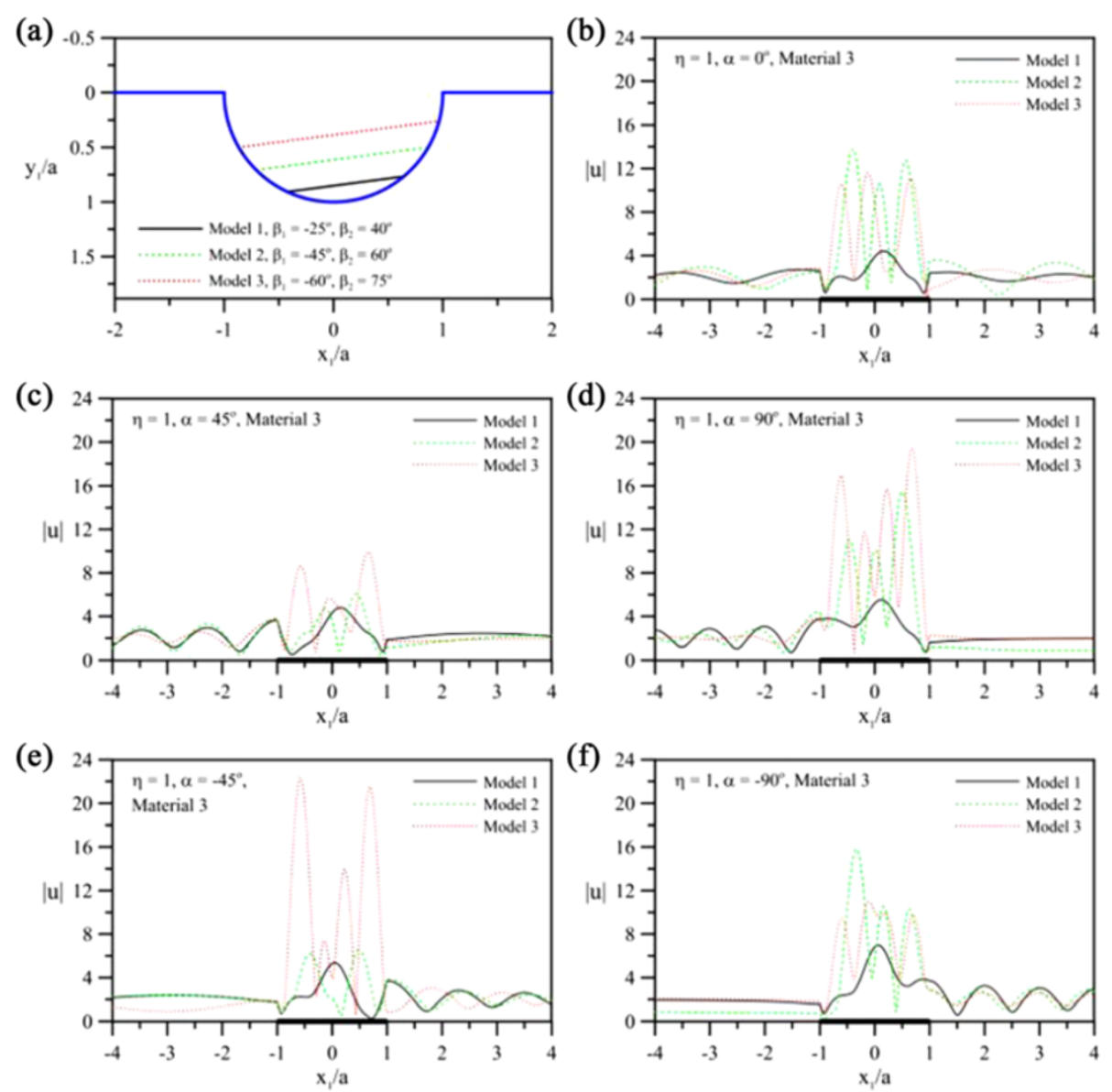

Figure 3 Valley geometries for models 1 to 3 and surface motions. (a) Valley geometries for models 1 to 3 are displayed. Surface motions versus $x_{1} / a$ for different filling levels with material 3 at $\eta=1$ : (b) $a=0^{\circ}$, (c) $a=45^{\circ}$, (d) $a=90^{\circ}$, (e) $a=-45^{\circ}$, and (f) $a=-90^{\circ}$.

amplitudes increases when the filling level of the alluvial layer rises.

Figure $4 \mathrm{a}$ illustrates the three valley geometries for models 4 to 6: model 4 is a horizontally filled case with $\beta_{1}=-53.1301^{\circ}$ and $\beta_{2}=53.1301^{\circ}$, model 5 a slightly obliquely filled case with $\beta_{1}=-48.2934^{\circ}$ and $\beta_{2}=58.2934^{\circ}$, and model 6 , a moderately obliquely filled case with $\beta_{1}=-43.7802^{\circ}$ and $\beta_{2}=63.7802^{\circ}$. To demonstrate the influence of the inclination of filling layer (with material 3 ) on the displacement amplitudes, the computed results with a range of incident angles at $\eta=0.5$ are displayed in Figure $4 \mathrm{~b}, \mathrm{c}, \mathrm{d}, \mathrm{e}, \mathrm{f}$. From models 4 to 6 (see Figure $4 \mathrm{a}$ ), the top surface of the filling layer gradually rotates counterclockwise with respect to an axis at $\left(x_{1} / a, y_{1} / a\right)=$ $(0,0.6)$. This makes the locations of maximum displacement amplitudes shift to the right (see Figure 4b,c,d,e,f). If the low-frequency waves come from the lower left quadrant $\left(\alpha=45^{\circ}\right.$ and $\left.90^{\circ}\right)$, the peak amplitudes of motions may go down (see Figure 4c,d). The main reason for this change is that more wave energy is straightforwardly reflected back into the bedrock due to increments in the circular-arc free surface at the left-hand side of the valley. On the contrary, the peak amplitudes of motions may increase (see Figure 4e,f) because more wave energy is transmitted through the soil-bedrock interface into the alluvial layer when the low-frequency waves emanate from the lower right quadrant $\left(\alpha=-45^{\circ}\right.$ and $\left.-90^{\circ}\right)$. Motions on the horizontal surface are insensitive to variations in inclinations of filling layer, especially for those in the shielded region. Such a feature can be also found in the vertically incident case (see Figure $4 \mathrm{~b}$ ).

Figure 5 displays the displacement amplitudes versus the dimensionless horizontal distance and the incident angle for three models with material 3 to manifest the influence of incident angles on the surface motions. Each subdiagram in Figure 5 comprises a total of 400 simulations with computational times of 15 to $44 \mathrm{~min}$. During one simulation step, 400 data points along the $x_{1}$ direction are calculated for a fixed value of $\alpha$. At low frequency $(\eta=1)$, the amplitudes are high when $-40^{\circ} \leq \alpha \leq-20^{\circ}$ and $90^{\circ} \leq \alpha \leq-80^{\circ}$ for the lowly filled case (Figure $5 \mathrm{a}$ ) and when $0^{\circ} \leq|\alpha| \leq 20^{\circ}$ and $70^{\circ} \leq|\alpha| \leq 90^{\circ}$ for the intermediately filled 

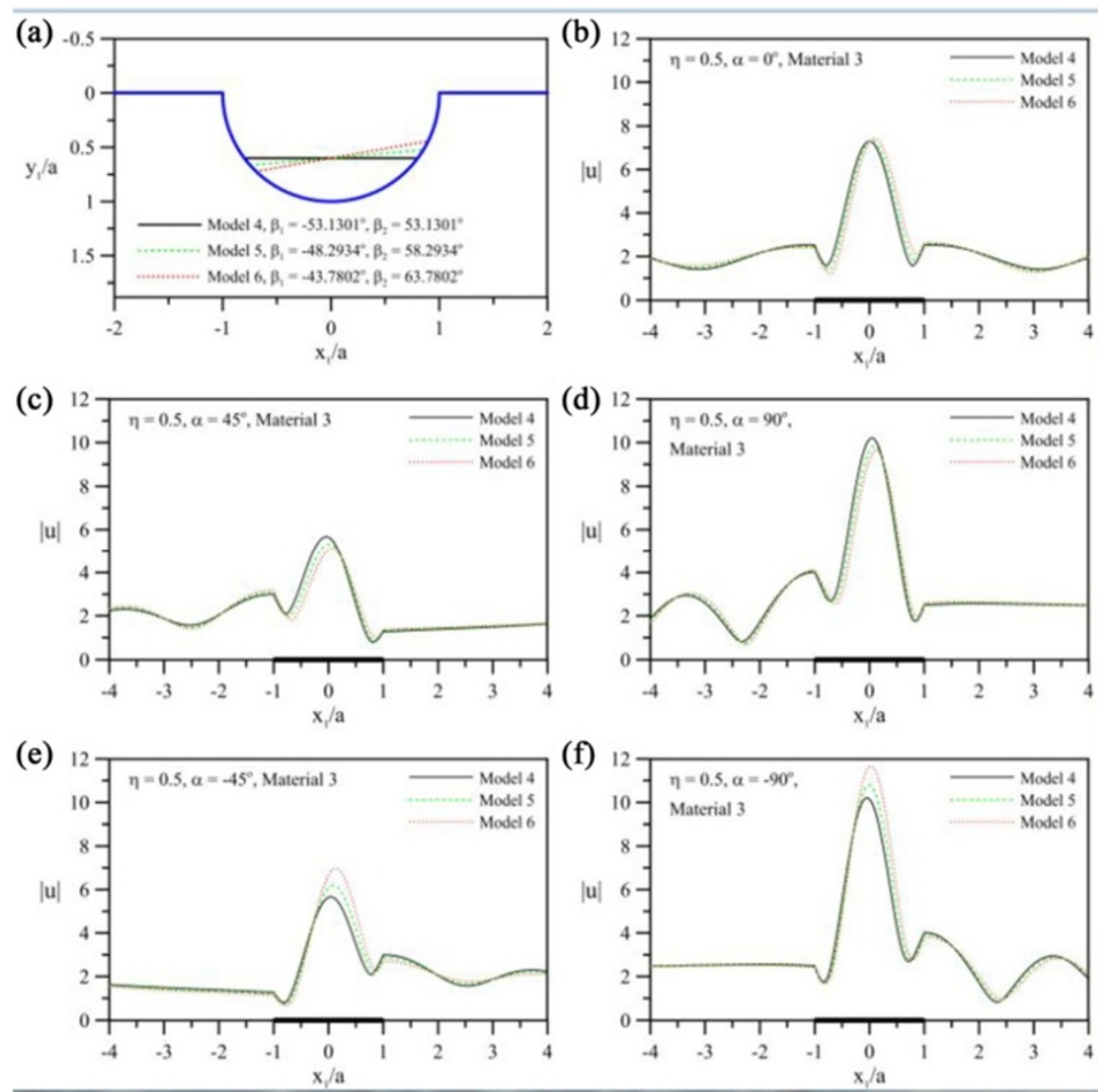

Figure 4 Valley geometries for models 4 to 6 and surface motions. (a) Valley geometries for models 4 to 6 are displayed. Surface motions versus $x_{1} / a$ for different inclinations of filling layers with material 3 at $\eta=0.5$ : (b) $a=0^{\circ}$, (c) $a=45^{\circ}$, (d) $a=90^{\circ}$, (e) $a=-45^{\circ}$, and (f) $a=-90^{\circ}$.

case (Figure 5c). As to the highly filled case (Figure 5e), the amplitudes are high except for those with $-30^{\circ} \leq \alpha \leq-10^{\circ}$ and $25^{\circ} \leq \alpha \leq 40^{\circ}$. For the high-frequency excitation $(\eta=7)$, the peak amplitudes inside the valley are at least five times larger than those on the free field (see Figure 5b,d,f).

In order to demonstrate the effect of dimensionless frequencies on surface motions around the valley, we compute the spectral variations in displacement amplitudes for model 2 with material 3 . Results are shown in Figure $6 a, b, c, d, e, f$ with $\alpha=0^{\circ}, 30^{\circ}, 60^{\circ}, 90^{\circ},-45^{\circ}$, and $90^{\circ}$, respectively. Each sub-diagram in Figure 6 consists of $400 \times 400$ grid squares, and the computational times are about 1.2 to $2.6 \mathrm{~h}$. For vertical incidence $\left(\alpha=0^{\circ}\right)$ in Figure $6 \mathrm{a}$, the intense ground shaking (in the red region) appears almost near the center of the upper face of the alluvium and near the two intersections of the inclined and curved surfaces of the valley, especially when $\eta \geq 11$. For oblique incidence in Figure 6b,c,e, the average peak values may be 10 or 11 . For horizontal incidence $\left(\alpha=90^{\circ}\right.$ and $\left.-90^{\circ}\right)$, the focusing of wave energy can almost be observed at $x_{1} / a=0.6$ in Figure $6 \mathrm{~d}$ and at $x_{1} / a=-0.4$ in Figure $6 \mathrm{f}$. This may be attributed to the constructive interference between multiple reflected waves within the alluvial layer. In the upper corner on the illuminated side of the valley $\left(x_{1} / a=-1\right.$ in Figure $6 \mathrm{~d}$ and $x_{1} / a=1$ in Figure $6 f$ ), the displacement amplitudes are very close to 4 , which is a theoretical value of the quarter-plane problem (see e.g., Sánchez-Sesma 1985). Under horizontal incidence, the average maximum amplification can be up to eight times larger than that at the free field.

Figure 7a,b,c,d,e,f exhibits the influence of soil/bedrock stiffness ratios $\left(\mu_{2} / \mu_{1}\right)$ upon displacement amplitudes for model 1 with $\eta=2$ at $\alpha=0^{\circ}, 30^{\circ}, 60^{\circ}, 90^{\circ},-45^{\circ}$, and $-90^{\circ}$, respectively. It is clear from the figures that the surface motions inside the valley become more oscillatory and complicated as the filling layer gets softer. The peak amplitude increases with decreasing $\mu_{2} / \mu_{1}$, and the value may reach at least 16 for grazing incidence (Figure $7 d, f$ ). For the softer case (material 3, shown by red dotted lines), the peak amplitudes under vertical and oblique incidence 


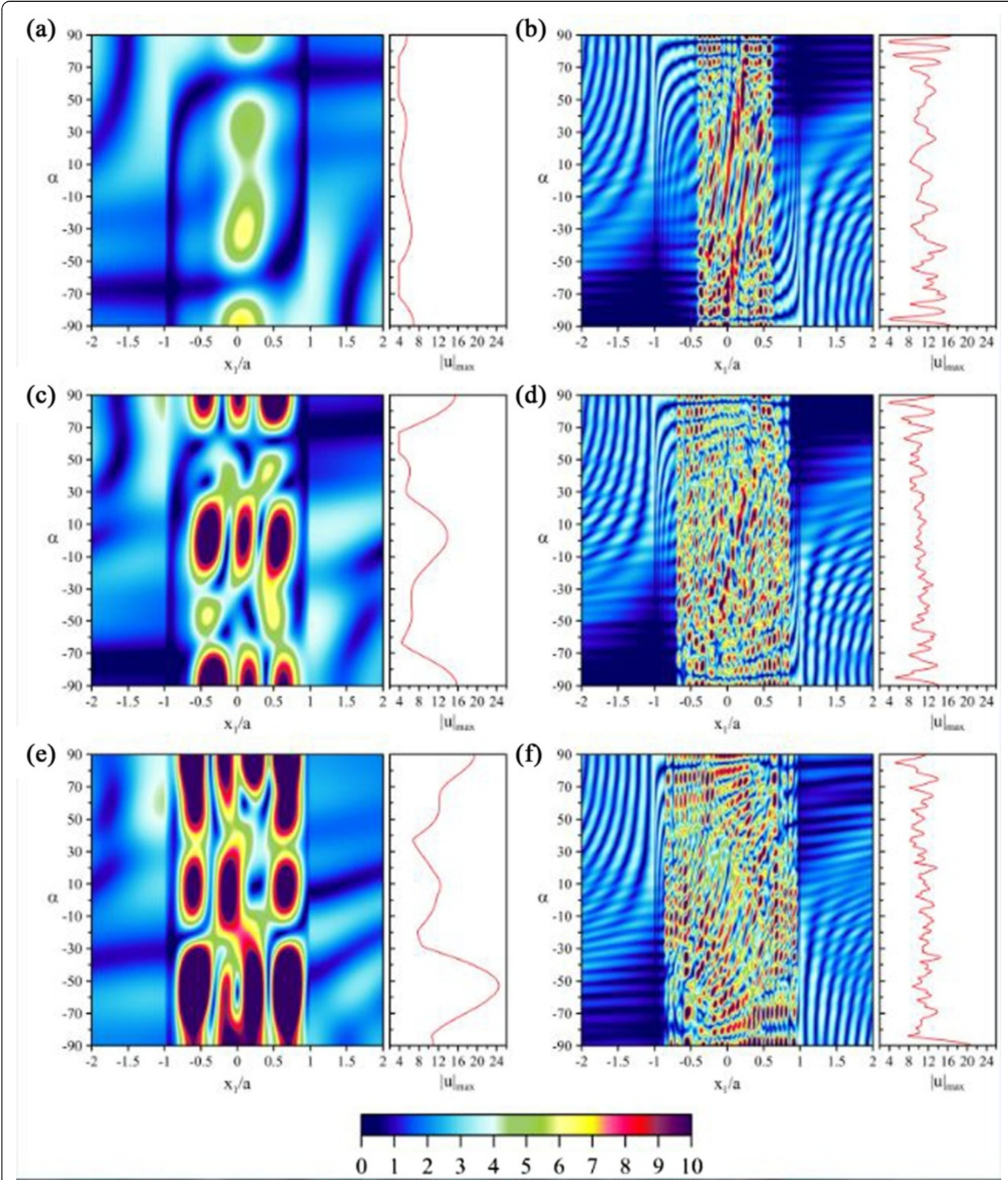

Figure 5 Surface motions versus $\boldsymbol{x}_{\mathbf{1}} / \boldsymbol{a}$ and $\boldsymbol{a}$ for different models with material $\mathbf{3}$. (a) model 1 at $\eta=1$, (b) model 1 at $\eta=7$, (c) model 2 at $\eta=1$, (d) model 2 at $\eta=7$, (e) model 3 at $\eta=1$, and (f) model 3 at $\eta=7$.

(see Figure 7a,b,c,e) are smaller than those under horizontal incidence (Figure 7d,f). For oblique and grazing incidence, the motion pattern in the illuminated region $\left(x_{1} / a<-1\right.$ in Figure $7 \mathrm{~b}, \mathrm{c}, \mathrm{d}$ or $x_{1} / a>1$ in Figure $\left.7 \mathrm{e}, \mathrm{f}\right)$ is less sensitive than those in the shielded region $\left(x_{1} / a>1\right.$ in Figure $7 \mathrm{~b}, \mathrm{c}, \mathrm{d}$ or $x_{1} / a<-1$ in Figure $\left.7 \mathrm{e}, \mathrm{f}\right)$. 


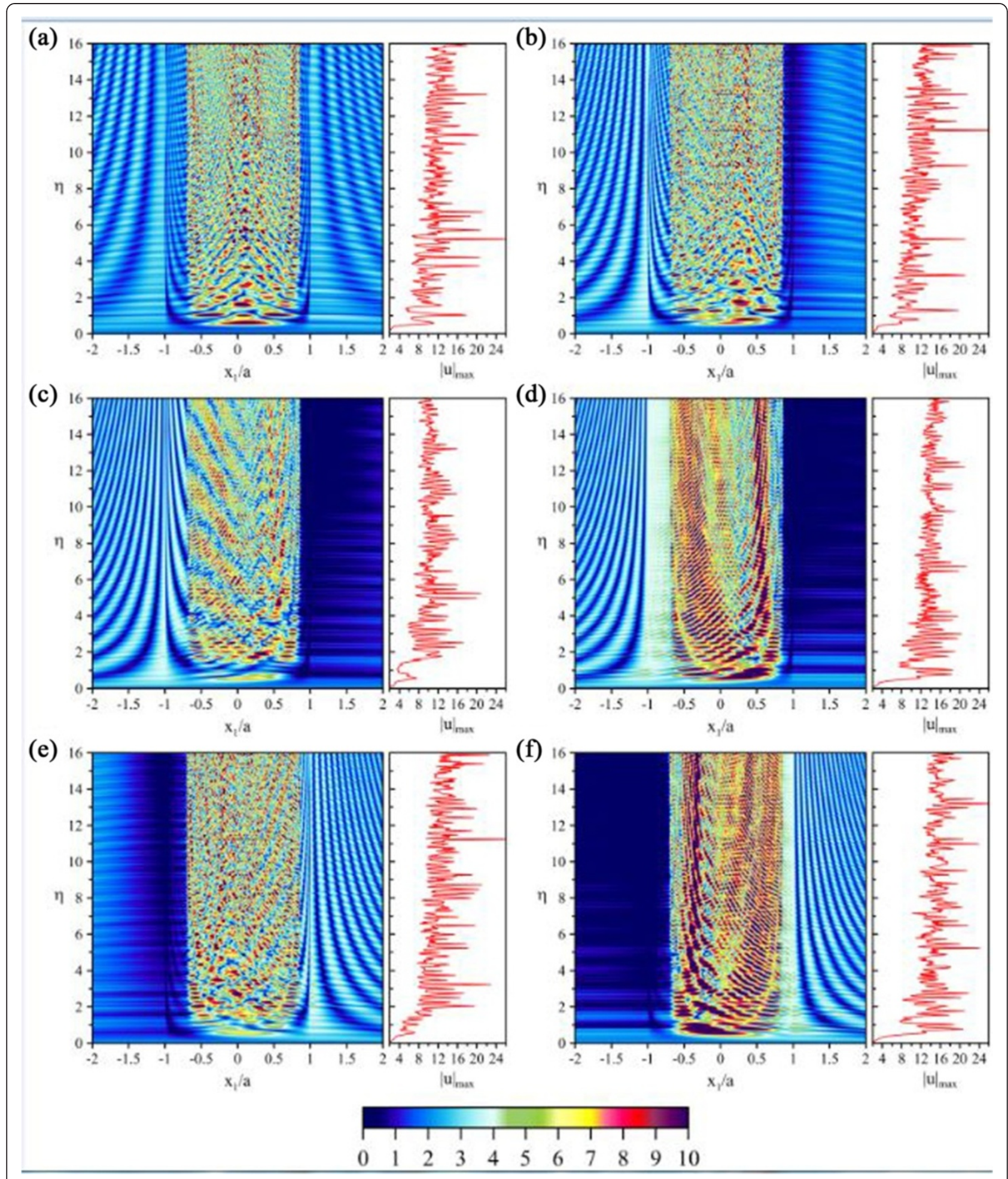

Figure 6 Spectral variations in surface motions around the valley for model 2 with material 3. (a) $a=0^{\circ}$, (b) $a=30^{\circ}$, (c) $a=60^{\circ}$, (d) $a=90^{\circ}$, (e) $a=-45^{\circ}$, and (f) $a=-90^{\circ}$. 

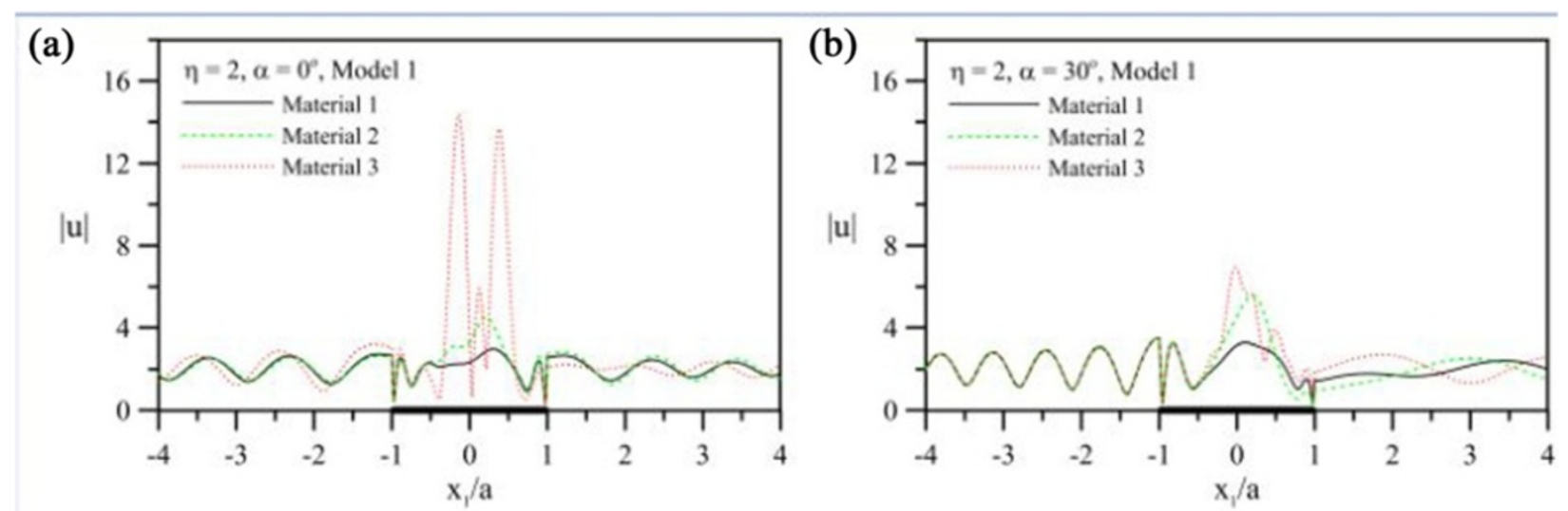

(c)

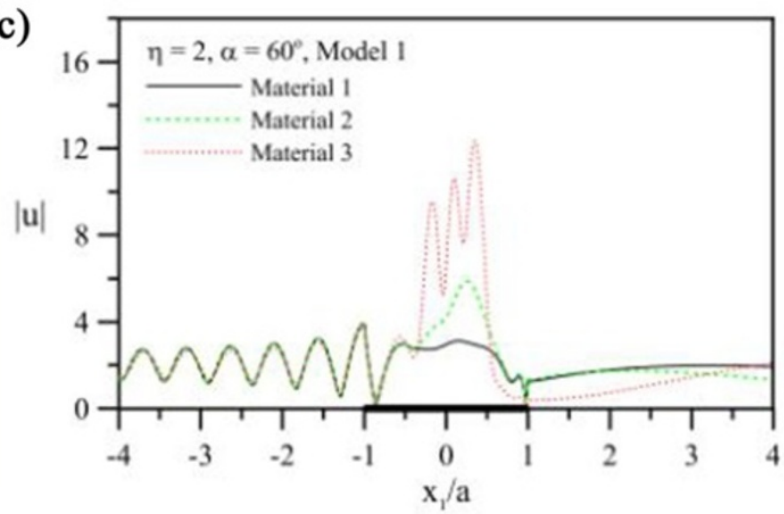

(e)

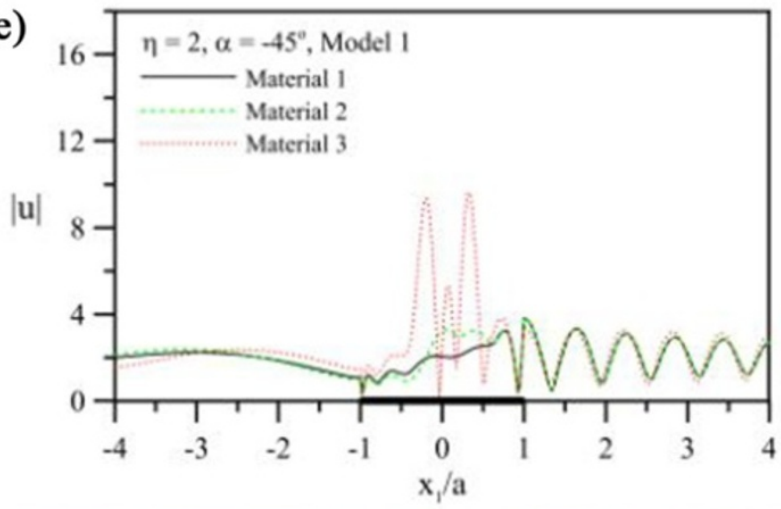

(d)

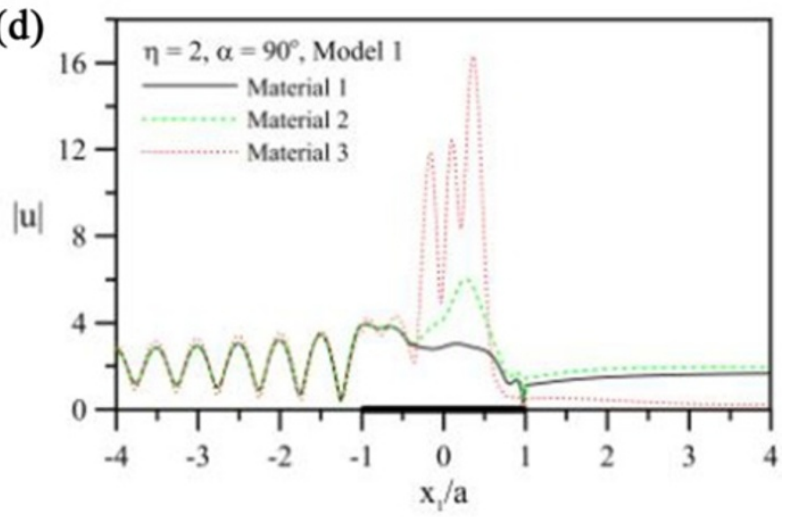

(f)

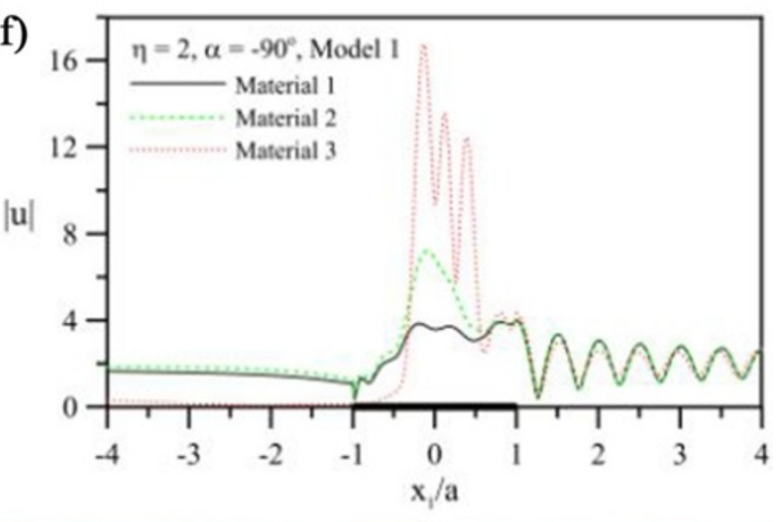

Figure 7 Surface motions versus $x_{1} / a$ for model 1 with different stiffness ratios at $\boldsymbol{\eta}=2$. (a) $a=0^{\circ}$, (b) $a=30^{\circ}$, (c) $a=60^{\circ}$, (d) $a=90^{\circ}$, (e) $a=-45^{\circ}$, and (f) $a=-90^{\circ}$.

Overall, the surface motions within and around the valley are dependent not only on the filling level and mechanical properties of alluvial layers but also on the frequency and incident angle of input waves.

\section{Surface and subsurface motions in the time domain}

Using the fast Fourier transform algorithm, one may examine the response in the time domain. The incident signal is a symmetric Ricker wavelet (Ricker 1945), which is defined as

$$
u(t)=\left(2 \pi^{2} f_{\mathrm{c}}^{2} t^{2}-1\right) \exp \left(-\pi^{2} f_{\mathrm{c}}^{2} t^{2}\right),
$$

where $f_{\mathrm{c}}$ is the characteristic frequency and is set to be $2 \mathrm{~Hz}$. Computations are made at discrete frequencies ranging from 0 to $8 \mathrm{~Hz}$ with an interval of $0.0625 \mathrm{~Hz}$. The half-width of the valley top and the outer shearwave velocity are $1 \mathrm{~km}$ and $1 \mathrm{~km} / \mathrm{s}$, respectively. The reference point for $t=0$ when the plane waves pass by is specified at the position $\left(x_{1}, y_{1}\right)=(0 \mathrm{~km}, 4 \mathrm{~km})$ for vertical incidence and at $\left(x_{1}, y_{1}\right)=(-4 \mathrm{~km}, 0 \mathrm{~km})$ for grazing incidence. 
Synthetic seismograms are shown in Figure 8 for model 1 with material 2 and in Figure 9 for model 2 with material 2. Figures $8 \mathrm{a}$ and $9 \mathrm{a}$ correspond to vertical incidence $\left(\alpha=0^{\circ}\right)$, while Figures $8 \mathrm{~b}$ and $9 \mathrm{~b}$ to oblique incidence $\left(\alpha=30^{\circ}\right)$. In Figures 8 and 9 , the time series are plotted at 101 locations with equal spacing of $0.1 \mathrm{~km}$ from $x_{1}=-4$ to $6 \mathrm{~km}$. Due to constructive interference between multiple reflections from the alluvium top and

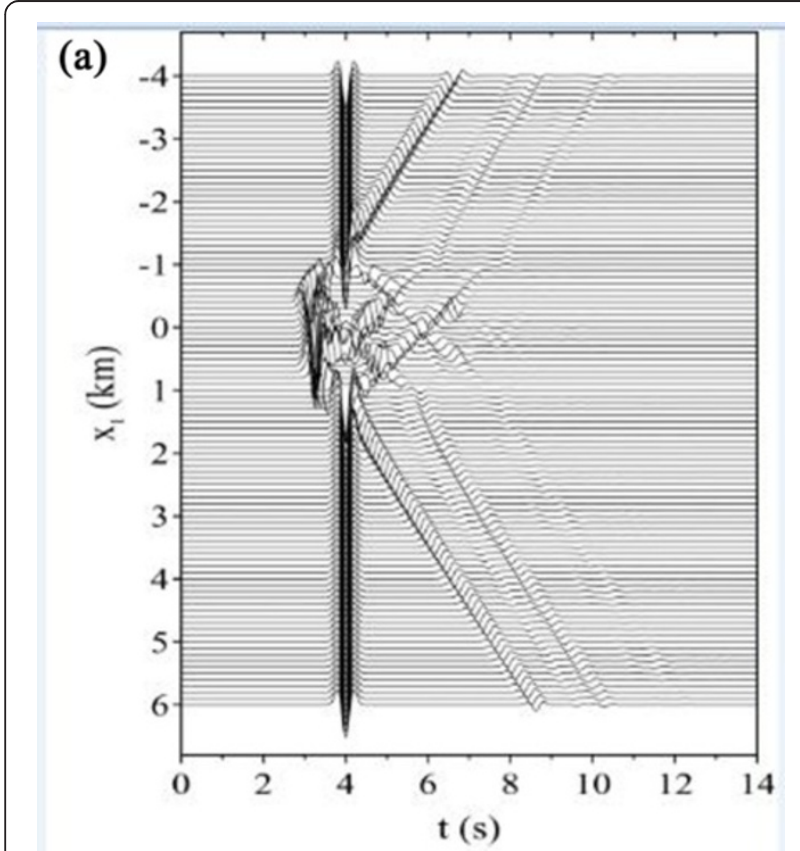

(b)

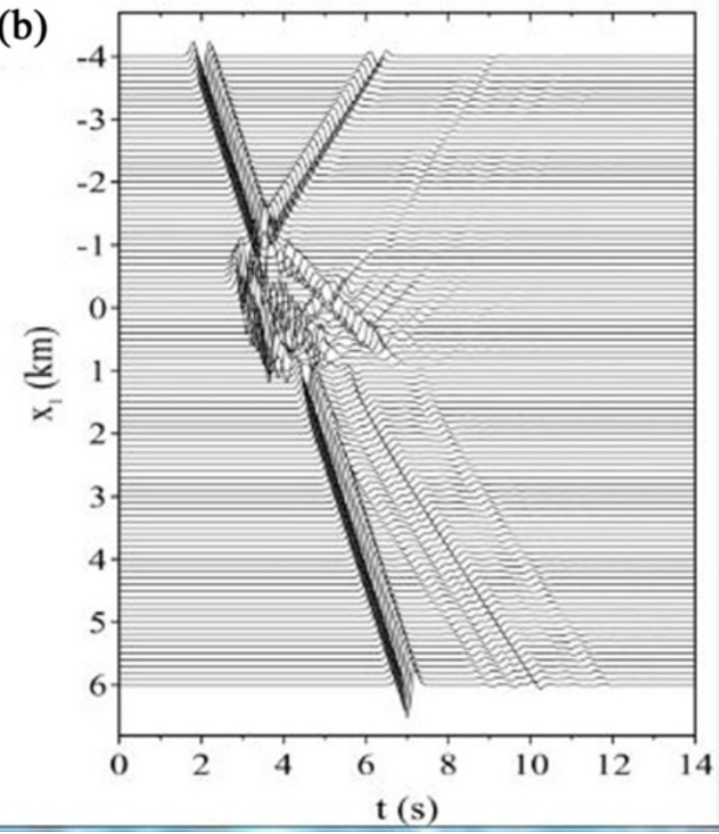

Figure 8 Synthetic seismograms for model 1 with material 2 at $f_{\mathrm{c}}=2 \mathrm{~Hz}$. (a) $a=0^{\circ}$ and (b) $a=30^{\circ}$.
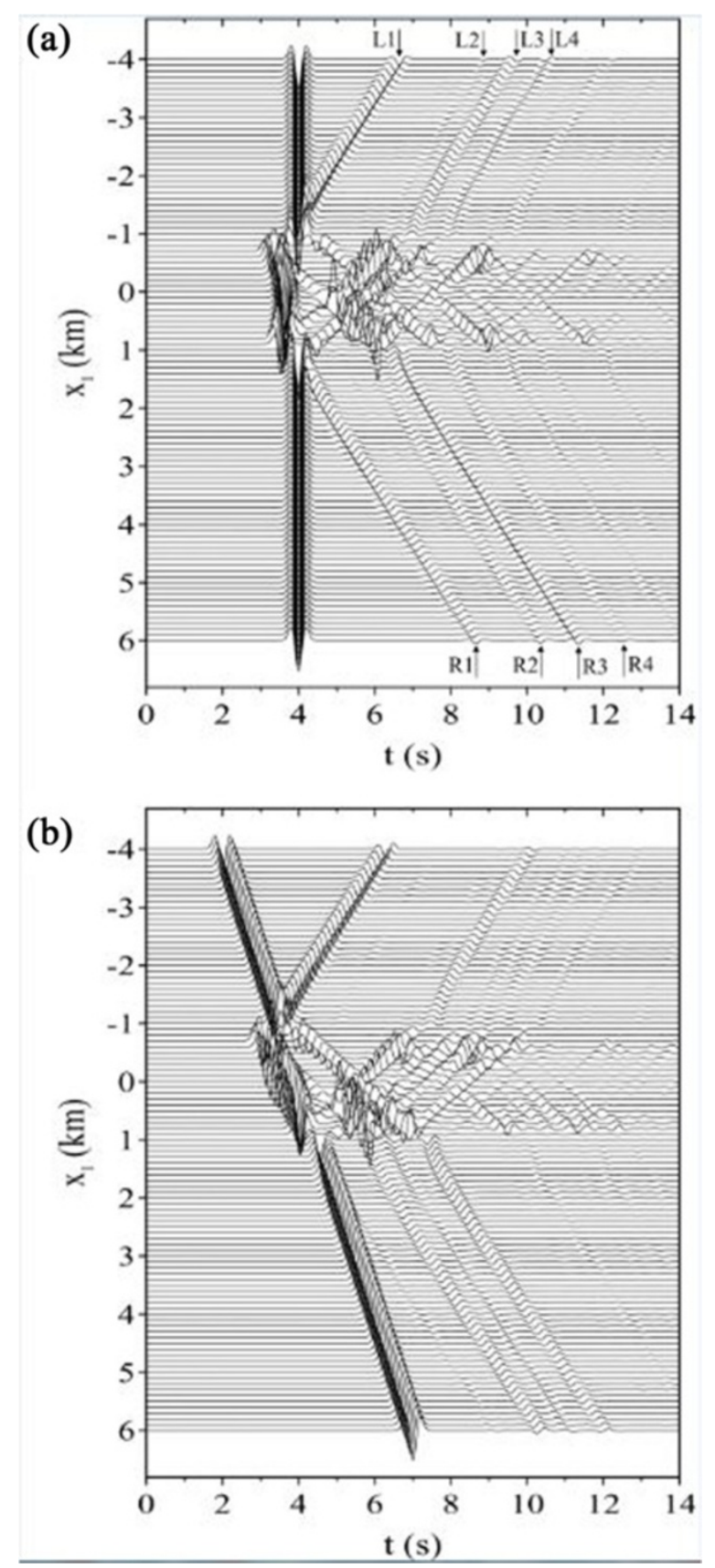

Figure 9 Synthetic seismograms for model 2 with material 2 at $f_{\mathbf{c}}=\mathbf{2 ~ H z}$. (a) $a=0^{\circ}$ and (b) $a=30^{\circ}$.

the soil-bedrock interface, signal enhancement within the filling region can be observed in Figures 8 and 9. For oblique incidence (see Figures $8 \mathrm{~b}$ and $9 \mathrm{~b}$ ), the shielding effect of the valley makes the displacement amplitudes near the upper right corner of the valley $\left(x_{1}=1 \mathrm{~km}\right)$ smaller than those of direct waves.

Comparing Figure 8 with Figure 9, the total response duration for the lowly filled case is shorter than that for the intermediately filled case. This is due to the fact that 
most of the wave energy is transmitted back into the half plane in the former case, while more wave energy is trapped within the alluvium in the latter case. The peak amplification for the intermediately filled case is larger than that for the lowly filled case. In Figure 9b, the amplification of surface motions in the intermediately filled case can be up to about three times larger than that in the free field. In addition, several late-arriving signals after the direct waves are in turn labeled on the top and bottom of Figure 9a by arrows $L 1, L 2, R 1, R 2$, etc. In order to explain the sources of these marked phases, we produced Figure 10, which shows ten snapshots of transient subsurface motions for model 2 with material 2 under vertical incidence $\left(\alpha=0^{\circ}\right)$. At each time instant, an overall view of motions around the valley is displayed in the left-hand frame, while a close-up view of motions within the alluvial layer is displayed in the right-hand frame. The arrows in Figure 10 correspond to those marked in Figure 9a.
Figure 10a shows that the incident pulse is partly reflected and partly transmitted at the soil-bedrock interface. The waves entering the deposits slow down and bend downwards because the input signal moves from a high-velocity layer to a low-velocity one. Figure 10b shows that two scattered waves (marked by white crosses) are generated when the incident pulse passes through the lower corners of the valley. The geometric spreading of reflected waves from the valley bottom (displayed with white asterisks in Figure 10a,b,c,d,e,f,g) reaches the horizontal ground surface and couples with scattered waves $L 1$ and $R 1$ generated from the upper corners of the valley (see Figure 10c,d,e,f,g). Reflected waves from the inclined surface of the valley (displayed with white hollow triangles in Figure 10b,c,d,e) cross through the soilbedrock interface, then interact with scattered waves from the lower corners of the valley, and finally trigger scattered waves $R 2$ and $L 2$ from the upper corners of the valley (see Figure 10f,g,h,i,j). The amplitudes of scattered waves

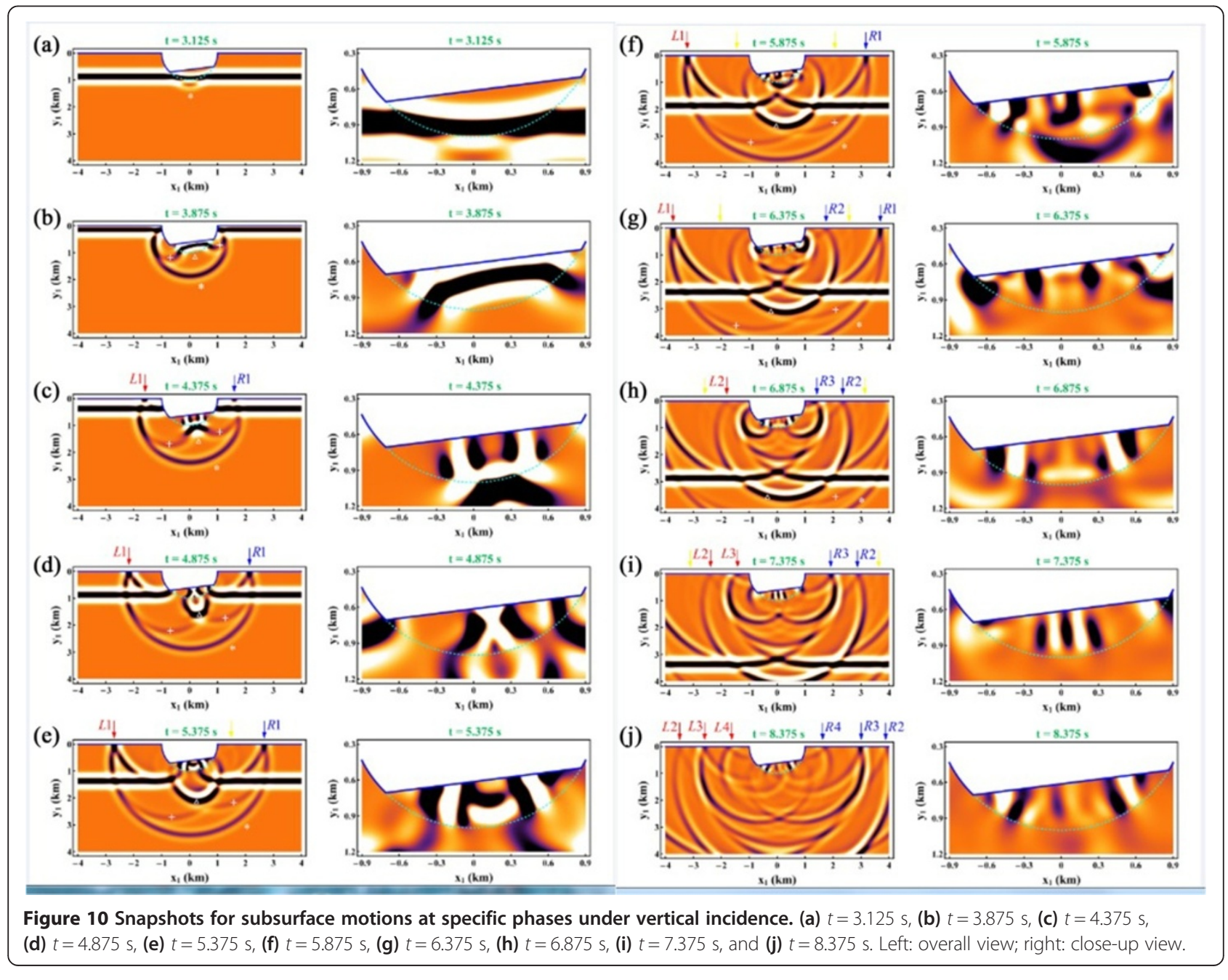


induced by reflected waves from the horizontal ground surface (see those displayed with yellow arrows in Figure $10 \mathrm{e}, \mathrm{f}, \mathrm{g}, \mathrm{h}, \mathrm{i})$ are much weaker than those from the valley corners. Hence, it is not easy to recognize the scattered waves from valley corners in Figure 9a. The scattered waves $R 3, L 3, R 4$, and $L 4$ (see Figure $10 \mathrm{~h}, \mathrm{i}, \mathrm{j}$ ) can be generated from the waves transmitted from the lower corners of the valley. Overall, the upper and lower corners of the valley behave as new sources to generate waves.

Figure 10c,d,e,f,g,h,i,j reveals that the surface waves emerge from the lower corners of the valley and travel along the topmost alluvial layer in opposite directions. The reflected waves continue to bounce back and forth between the bimaterial interface and the inclined zero-stress surface. This traps energy within the low-velocity filling layer. Interaction and interference between surface waves and multiple reflected waves are responsible for a long duration of ground shaking, amplified ground motions, and complicated waveforms in the alluvial region.

\section{Conclusions}

Herein, the problem of SH-wave scattering, induced by a semi-circular valley partially filled with an inclined alluvial layer, has been tackled and solved theoretically. The use of the robust RMT has given rise to a rigorous series solution. A novel form of Graf's addition formula is derived for angular wavefunctions constrained by an inclined free surface so that it is more general than those given in the literature for a horizontal free surface. With the aid of such a newly derived version of Graf's addition formula, the coordinate transformation for Bessel functions between two arbitrarily located polar coordinate systems can be performed conveniently. Disturbances in antiplane displacement fields have been evaluated and analyzed in both the frequency and time domains. Approximations of the extremely lowly filled valleys are consistent with the completely empty canyons, and approximations of the extremely highly filled valleys with the fully filled valleys. The frequency-domain results indicate that the peak amplitudes of motions may increase at low frequencies when the top surface of the filling layer steepens towards the illuminated region (i.e., the region facing the incident waves). If the incident angle bends towards the horizontal ground surface, the phenomenon of wave focusing is found to be significant, and spectral amplifications might reach up to approximately 8 . The timedomain results show that the dynamic response of the valley is closely related to the interaction and interference between the surface waves and multiple reflected waves within the alluvial layer. The computed results presented herein can serve as a benchmark to validate mesh-based numerical simulations.

\section{Appendix 1}

Pertinent functions in Equations 14, 20, and 21

The related functions in Equation 14 are given by

$$
\begin{aligned}
F_{m, n}^{C} & =\frac{\varepsilon_{m}}{2}\left\{(-1)^{n} J_{m+n}\left(k_{2} r_{e}\right) \cos \left[(m+n) \varphi+n \theta_{e}\right](39)\right. \\
& \left.+J_{m-n}\left(k_{2} r_{e}\right) \cos \left[(m-n) \varphi-n \theta_{e}\right]\right\} \\
F_{m, n}^{S} & =\frac{\varepsilon_{m}}{2}\left\{(-1)^{n} J_{m+n}\left(k_{2} r_{e}\right) \sin \left[(m+n) \varphi+n \theta_{e}\right](40)\right. \\
& \left.+J_{m-n}\left(k_{2} r_{e}\right) \sin \left[(m-n) \varphi-n \theta_{e}\right]\right\}
\end{aligned}
$$

The functions used in Equations 20 and 21 are as follows:

$$
I_{m, n}^{C}=\left\{\begin{array}{l}
\beta_{2}-\beta_{1}, \quad m=n=0 \\
\frac{\beta_{2}-\beta_{1}}{2}+\frac{\sin 2 n \beta_{2}-\sin 2 n \beta_{1}}{4 n}, m=n \neq 0 \\
{\left[m\left(\sin m \beta_{2} \cos n \beta_{2}-\sin m \beta_{1} \cos n \beta_{1}\right)\right.} \\
\left.+n\left(\sin n \beta_{1} \cos m \beta_{1}-\sin n \beta_{2} \cos m \beta_{2}\right)\right] / \\
\left(m^{2}-n^{2}\right), \quad m \neq n
\end{array}\right.
$$

$$
I_{m, n}^{S}=\left\{\begin{array}{l}
\frac{\beta_{2}-\beta_{1}}{2}+\frac{\sin 2 n \beta_{1}-\sin 2 n \beta_{2}}{4 n}, \quad m=n \\
{\left[m\left(\sin n \beta_{1} \cos m \beta_{1}-\sin n \beta_{2} \cos m \beta_{2}\right)\right.} \\
\left.+n\left(\sin m \beta_{2} \cos n \beta_{2}-\sin m \beta_{1} \cos n \beta_{1}\right)\right] / \\
\left(m^{2}-n^{2}\right), \quad m \neq n
\end{array},\right.
$$

$$
I_{m, n}^{S C}=\left\{\begin{array}{c}
\frac{\cos 2 n \beta_{1}-\cos 2 n \beta_{2}}{4 n}, \quad m=n \\
{\left[m\left(\cos m \beta_{1} \cos n \beta_{1}-\cos m \beta_{2} \cos n \beta_{2}\right)\right.} \\
\left.+n\left(\sin m \beta_{1} \sin n \beta_{1}-\sin m \beta_{2} \sin n \beta_{2}\right)\right] / \\
\left(m^{2}-n^{2}\right), \quad m \neq n
\end{array}\right.
$$

\section{Appendix 2}

\section{Pertinent functions in Equations 25 and 26}

The functions associated with Equations 25 and 26 are as follows:

$$
\begin{aligned}
R_{q, n}^{C} & =G_{n, 2 q}^{C}-\frac{\mu_{2}}{\pi \mu_{1}} \sum_{p=0}^{\infty} \varepsilon_{p} \tilde{G}_{n, 2 p}^{C} \tilde{H}_{2 p} I_{2 p, 2 q}^{C} \\
& -\frac{2 \mu_{2}}{\pi \mu_{1}} \sum_{p=0}^{\infty} \tilde{G}_{n, 2 p+1}^{S} \tilde{H}_{2 p+1} I_{2 p+1,2 q}^{S C}, \\
R_{q, n}^{S} & =G_{n, 2 q+1}^{S}-\frac{\mu_{2}}{\pi \mu_{1}} \sum_{p=0}^{\infty} \varepsilon_{p} \tilde{G}_{n, 2 p}^{C} \tilde{H}_{2 p} I_{2 q+1,2 p}^{S C} \\
& -\frac{2 \mu_{2}}{\pi \mu_{1}} \sum_{p=0}^{\infty} \tilde{G}_{n, 2 p+1}^{S} \tilde{H}_{2 p+1} I_{2 p+1,2 q+1}^{S},
\end{aligned}
$$




$$
\begin{aligned}
L_{q}^{C} & =-\frac{4 i}{\pi a} \sum_{n=0}^{\infty} \frac{\varepsilon_{n}(-1)^{n} \cos (2 n \alpha)}{H_{2 n}^{(2)^{\prime}}\left(k_{1} a\right)} I_{2 n, 2 q}^{C} \\
& -\frac{8}{\pi a} \sum_{n=0}^{\infty} \frac{(-1)^{n} \sin [(2 n+1) \alpha]}{H_{2 n+1}^{(2)^{\prime}}\left(k_{1} a\right)} I_{2 n+1,2 q}^{S C}, \\
L_{q}^{S} & =-\frac{4 i}{\pi a} \sum_{n=0}^{\infty} \frac{\varepsilon_{n}(-1)^{n} \cos (2 n \alpha)}{H_{2 n}^{(2)^{\prime}}\left(k_{1} a\right)} I_{2 q+1,2 n}^{S C} \\
& -\frac{8}{\pi a} \sum_{n=0}^{\infty} \frac{(-1)^{n} \sin [(2 n+1) \alpha]}{H_{2 n+1}^{(2)^{\prime}}\left(k_{1} a\right)} I_{2 n+1,2 q+1}^{S},
\end{aligned}
$$

together with

$$
\begin{aligned}
G_{n, q}^{C} & =\sum_{m=0}^{\infty}\left(F_{m, n}^{C} I_{m, q}^{C}+F_{m, n}^{S} I_{m, q}^{S C}\right) J_{m}\left(k_{2} a\right) \\
G_{n, q}^{S} & =\sum_{m=0}^{\infty}\left(F_{m, n}^{C} I_{q, m}^{S C}+F_{m, n}^{S} I_{m, q}^{S}\right) J_{m}\left(k_{2} a\right) \\
\tilde{H}_{p} & =\frac{H_{p}^{(2)}\left(k_{1} a\right)}{H_{p}^{(2)^{\prime}}\left(k_{1} a\right)}
\end{aligned}
$$

\section{Competing interests}

The authors declare that they have no competing interests.

\section{Authors' contributions}

$\mathrm{KHC}$ completed the theoretical derivation, conducted the analysis, and drafted the manuscript. DHT and JHW participated in the design of the study and helped to improve the manuscript. All authors read and approved the final manuscript.

\section{Acknowledgements}

The authors are much obliged to the editor, Dr. Tatsuhiko Hara, and two reviewers for their encouragement and insightful and valuable suggestions and comments that have improved this paper. Additionally, the first and third authors are sincerely grateful for the financial support granted by the Ministry of Science and Technology, former National Science Council, Taiwan, Republic of China (Project Nos. NSC 102-2811-M-001-060 and NSC 102-2116-M-001-021, respectively).

\section{Author details}

${ }^{1}$ Institute of Earth Sciences, Academia Sinica, No. 128, Sec. 2, Academia Road, Nangang, Taipei, Taiwan 11529, Republic of China. ${ }^{2}$ Department of Harbor and River Engineering, National Taiwan Ocean University, No. 2, Beining Rd., Jhongjheng District, Keelung, Taiwan 20224, Republic of China.

\section{Received: 4 September 2013 Accepted: 7 March 2014}

Published: 12 June 2014

\section{References}

Abramowitz M, Stegun IA (eds) (1972) Handbook of mathematical functions: with formulas, graphs, and mathematical tables. Dover, New York

Aki K, Larner KL (1970) Surface motion of a layered medium having an irregular interface due to incident plane SH waves. J Geophys Res 75:933-954

Andersen S, Andersen L (2010) Modelling of landslides with the material-point method. Comput Geosci 14:137-147

Ávila-Carrera R, Sánchez-Sesma FJ (2013) The variational projection method (VPM): a modern technique to simulate the seismic response of shallow alluvial valleys. Soil Dyn Earthq Eng 50:134-142

Avilés J, Sánchez-Sesma FJ (1983) Piles as barriers for elastic waves. J Geotech Eng 109:1133-1146

Bard PY, Bouchon M (1980) The seismic response of sediment-filled valleys. Part 1: the case of incident SH waves. Bull Seismol Soc Am 70:1263-1286
Bielak J, Ghattas O, Kim EJ (2005) Parallel octree-based finite element method for large-scale earthquake ground motion simulation. Comput Model Eng Sci 10:99-112

Boore DM (2004) Can site response be predicted. J Earthq Eng 8:1-41 (special issue)

Boore DM, Larner KL, Aki K (1971) Comparison of two independent methods for the solution of wave-scattering problems: response of a sedimentary basin to vertically incident SH waves. J Geophys Res 76:558-569

Bordoni P, Haines J, Milana G, Marcucci S, Cara F, Di Giulio G (2011) Seismic response of L'Aquila downtown from comparison between $2 \mathrm{D}$ synthetics spectral ratios of SH, P-SV and Rayleigh waves and observations of the 2009 earthquake sequence. Bull Earthquake Eng 9:761-781

Boroschek RL, Contreras V, Kwak DY, Stewart JP (2012) Strong ground motion attributes of the $2010 \mathrm{Mw} 8.8$ Maule, Chile, earthquake. Earthq Spectra 28:S19-538

Bostock MG, Kennett BLN (1992) Multiple scattering of surface waves from discrete obstacles. Geophys J Int 108:52-70

Chang KH (2009) Scattering and diffraction of plane SH waves by surface and subsurface truncated circular discontinuities. National Taiwan Ocean University, Keelung, Taiwan, Ph.D. Dissertation

Chang KH, Tsaur DH, Wang JH (2013) Scattering of SH waves by a circular sectorial canyon. Geophys J Int 195:532-543

Chigira M, Wu X, Inokuchi T, Wang G (2010) Landslides induced by the 2008 Wenchuan earthquake, Sichuan, China. Geomorphology 118:225-238

Clements DL, Larsson A (1994) A note on surface motion of inhomogeneous alluvial valleys due to incident plane $\mathrm{SH}$ waves. Bull Seismol Soc Am 84:192-201

De Luca G, Marcucci S, Milana G, Sanò T (2005) Evidence of low-frequency amplification in the city of L'Aquila, central Italy, through a multidisciplinary approach including strong- and weak-motion data, ambient noise, and numerical modeling. Bull Seismol Soc Am 95:1469-1481

Delépine N, Semblat JF (2012) Site effects in an alpine valley with strong velocity gradient: interest and limitations of the 'classical' BEM. Soil Dyn Earthq Eng 38:15-24

Dravinski M (2007) Scattering of waves by a sedimentary basin with a corrugated interface. Bull Seismol Soc Am 97:256-264

Dravinski M, Mossessian TK, Eshraghi H, Kagami H (1991) Predominant motion of the Los Angeles sedimentary basin. Eng Anal Boundary Elem 8:206-214

Engquist B, Fokas A, Hairer E, Iserles A (eds) (2009) Highly oscillatory problems. London mathematical society lecture note series, vol 366. Cambridge University Press, Cambridge

Ewald M, Igel H, Hinzen KG, Scherbaum F (2006) Basin-related effects on ground motion for earthquake scenarios in the Lower Rhine Embayment. Geophys J Int 166:197-212

Frischknecht C, Rosset P, Wagner JJ (2005) Toward seismic microzonation-2-D modeling and ambient seismic noise measurements: the case of an embanked, deep Alpine valley. Earthq Spectra 21:635-651

Fu LY, Bouchon M (2004) Discrete wavenumber solutions to numerical wave propagation in piecewise heterogeneous media-l: theory of two-dimensional SH case. Geophys J Int 157:481-498

Gelagoti F, Kourkoulis R, Anastasopoulos I, Tazoh T, Gazetas G (2010) Seismic wave propagation in a very soft alluvial valley: sensitivity to ground-motion details and soil nonlinearity, and generation of a parasitic vertical component. Bull Seismol Soc Am 100:3035-3054

Ghofrani H, Atkinson GM, Goda K (2013) Implications of the 2011 M9.0 Tohoku Japan earthquake for the treatment of site effects in large earthquakes. Bull Earthquake Eng 11:171-203

Hovius N, Meunier P (2012) Earthquake ground motion and patterns of seismically induced landsliding. In: Clague JJ, Stead D (eds) Landslides: types, mechanisms and modeling. Cambridge University Press, Cambridge, pp 24-36

Huang MW, Wang JH, Hsieh HH, Wen KL, Ma KF (2005) Frequency-dependent sites amplifications evaluated from well-logging data in central Taiwan. Geophys Res Lett 32, L21302

Huang MW, Wang JH, Ma KF, Wang CY, Hung JH, Wen KL (2007) Frequencydependent site amplifications with $f \geq 0.01 \mathrm{~Hz}$ evaluated from the velocity and density models in central Taiwan. Bull Seismol Soc Am 97:624-637

Huang MW, Wang JH, Hsieh HH, Wen KL (2009) High frequency site amplification evaluated from borehole data in the Taipei Basin. J Seismol 13:601-611

Jing L, Stephansson O (2007) Fundamentals of discrete element methods for rock engineering: theory and applications. Developments in geotechnical engineering, vol 85. Elsevier, Amsterdam 
Kawase H, Aki K (1989) A study on the response of a soft basin for incident S, P, and Rayleigh waves with special reference to the long duration observed in Mexico City. Bull Seismol Soc Am 79:1361-1382

Keefer DK, Wartman J, Navarro Ochoa C, Rodriguez-Marek A, Wieczorek GF (2006) Landslides caused by the M 7.6 Tecomán, Mexico earthquake of January 21, 2003. Eng Geology 86:183-197

Kham M, Semblat JF, Bard PY, Dangla P (2006) Seismic site-city interaction: main governing phenomena through simplified numerical models. Bull Seismol Soc Am 96:1934-1951

Kham M, Semblat JF, Bouden-Romdhane N (2013) Amplification of seismic ground motion in the Tunis basin: numerical BEM simulations vs experimental evidences. Eng Geology 154:80-86

Koketsu K, Kikuchi M (2000) Propagation of seismic ground motion in the Kanto Basin, Japan. Science 288:1237-1239

Komatitsch D, Vilotte JP (1998) The spectral element method: an efficient tool to simulate the seismic response of $2 \mathrm{D}$ and $3 \mathrm{D}$ geological structures. Bull Seismol Soc Am 88:368-392

Kristek J, Moczo P, Galis M (2010) Stable discontinuous staggered grid in the finite-difference modelling of seismic motion. Geophys J Int 183:1401-1407

Lebedev NN (1965) Special functions and their applications. Prentice-Hall, Englewood Cliffs

Lee SJ, Chan YC, Komatitsch D, Huang BS, Tromp J (2009) Effects of realistic surface topography on seismic ground motion in the Yangminshan region of Taiwan based upon the spectral-element method and LiDAR DTM. Bull Seismol Soc Am 99:681-693

Lenti L, Martino S, Paciello A, Scarascia Mugnozza G (2009) Evidence of two-dimensional amplification effects in an alluvial valley (Valnerina, Italy) from velocimetric records and numerical models. Bull Seismol Soc Am 99:1612-1635

Ma S, Archuleta RJ, Page MT (2007) Effects of large-scale surface topography on ground motions, as demonstrated by a study of the San Gabriel Mountains, Los Angeles, California. Bull Seismol Soc Am 97:2066-2079

Makra K, Chávez-García FJ, Raptakis D, Pitilakis K (2005) Parametric analysis of the seismic response of a 2D sedimentary valley: implications for code implementations of complex site effects. Soil Dyn Earthq Eng 25:303-315

Marketos G, O'Sullivan C (2013) A micromechanics-based analytical method for wave propagation through a granular material. Soil Dyn Earthq Eng 45:25-34

Martin PA (2006) Multiple scattering: interaction of time-harmonic waves with N obstacles. Encyclopedia of mathematics and its applications, vol 107. Cambridge University Press, Cambridge

Moczo P, Kristek J, Galis M, Pazak P, Balazovjech M (2007) The finite-difference and finite-element modeling of seismic wave propagation and earthquake motion. Acta Phys Slovaca 57:177-406

Pelties C, Käser M, Hermann V, Castro CE (2010) Regular versus irregular meshing for complicated models and their effect on synthetic seismograms. Geophys J Int 183:1031-1051

Pratt TL, Brocher TM, Weaver CS, Creager KC, Snelson CM, Crosson RS, Miller KC, Tréhu AM (2003) Amplification of seismic waves by the Seattle basin, Washington State. Bull Seismol Soc Am 93:533-545

Ricker N (1945) The computation of output disturbances from amplifiers for true wavelet inputs. Geophysics 10:207-220

Sánchez-Sesma FJ (1985) Diffraction of elastic SH waves by wedges. Bull Seismol Soc Am 75:1435-1446

Smerzini C, Avilés J, Paolucci R, Sánchez-Sesma FJ (2009) Effect of underground cavities on surface earthquake ground motion under $\mathrm{SH}$ wave propagation. Earthq Eng Struct Dynam 38:1441-1460

Takekawa J, Mikada H, Goto T, Sanada Y, Ashida Y (2013) Coupled simulation of seismic wave propagation and failure phenomena by use of an MPS method. Pure Appl Geophys 170:561-570

Takenaka H, Ohori M, Koketsu K, Kennett BLN (1996) An efficient approach to the seismogram synthesis for a basin structure using propagation invariants. Bull Seismol Soc Am 86:379-388

Trifunac MD (1971) Surface motion of a semi-cylindrical alluvial valley for incident plane SH waves. Bull Seismol Soc Am 61:1755-1770

Trifunac MD (1973) Scattering of plane SH waves by a semi-cylindrical canyon Earthq Eng Struct Dynam 1:267-281

Tsaur DH (2011) Scattering and focusing of SH waves by a lower semielliptic convex topography. Bull Seismol Soc Am 101:2212-2219

Tsaur DH, Chang KH (2008a) SH-waves scattering from a partially filled semi-circular alluvial valley. Geophys J Int 173:157-167
Tsaur DH, Chang KH (2008b) An analytical approach for the scattering of SH waves by a symmetrical V-shaped canyon: shallow case. Geophys J Int $174: 255-264$

Tsaur DH, Chang KH (2009) Scattering and focusing of SH waves by a convex circular-arc topography. Geophys J Int 177:222-234

Tsaur DH, Chang KH (2012) Multiple scattering of SH waves by an embedded truncated circular cavity. J Mar Sci Tech 20:73-81

Tsaur DH, Hsu MS (2013) SH waves scattering from a partially filled semi-elliptic alluvial valley. Geophys J Int 194:499-511

Tsaur DH, Chang KH, Hsu MS (2010) An analytical approach for the scattering of SH waves by a symmetrical V-shaped canyon: deep case. Geophys J Int 183:1501-1511

Tucker BE, King U (1984) Dependence of sediment-filled valley response on input amplitude and valley properties. Bull Seismol Soc Am 74:153-165

Varadan VK, Varadan W, Pao YH (1978) Multiple scattering of elastic waves by cylinders of arbitrary cross section: I. SH waves J Acoust Soc Am 63:1310-1319

Virieux J, Etienne V, Cruz-Atienza V, Brossier R, Chaljub E, Coutant O, Garambois S, Mercerat D, Prieux V, Operto S, Ribodetti A, Tago J (2012) Modelling seismic wave propagation for geophysical imaging. In: Kanao M (ed) Seismic waves - research and analysis. InTech, Croatia, pp 253-304

Wang JH (2006) SAFE-Taipei: a program project for strong motions, active faults, and earthquakes in the Taipei metropolitan area. In: Chen YT (ed) Advances in geosciences, vol 1, Solid earth. World Scientific, Singapore, pp 61-74

Wang JH (2008) Urban seismology in the Taipei metropolitan area: review and perspective. Terr Atmos Ocean Sci 19:213-233

Wang KL (2010) Ground surface motions of oblique-truncated semicircular canyon. National Taiwan Ocean University, Keelung, Taiwan, Master's Thesis, In Chinese

Watson GN (1966) A treatise on the theory of Bessel functions, 2nd edn. Cambridge University Press, Cambridge

\section{doi:10.1186/1880-5981-66-53}

Cite this article as: Chang et al:: Ground motions around a semi-circular valley partially filled with an inclined alluvial layer under $\mathrm{SH}$-polarized excitation. Earth, Planets and Space 2014 66:53.

\section{Submit your manuscript to a SpringerOpen ${ }^{\circ}$ journal and benefit from:}

- Convenient online submission

- Rigorous peer review

- Immediate publication on acceptance

- Open access: articles freely available online

- High visibility within the field

- Retaining the copyright to your article

Submit your next manuscript at springeropen.com 